\title{
Producción de astaxantina en Haematococcus pluvialis bajo factores de estrés salino utilizando un biorreactor de $5 \mathrm{~L}$
}

\author{
Astaxanthin Production in Haematococcus pluvialis under \\ Salt Stress Factors Using a 5L Laboratory Bioreactor
}

\section{Ana Graciela Lancheros Díaz ${ }^{\text {ac }}$, Luis Eduardo Díaz Barrera ${ }^{\mathrm{b}}$, Judith Elena Camacho Kurmen ${ }^{\text {ad }}$}

\footnotetext{
a Grupo de Investigación Bioprocesos y Control, Programa Bacteriología y Laboratorio, Facultad de Ciencias de la Salud, Universidad Colegio Mayor de Cundinamarca, Colombia.

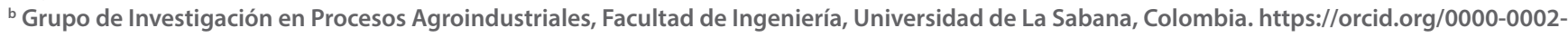
9588-9935

c https://orcid.org/0000-0002-5799-0282 | aglancheros@unicolmayor.edu.co

${ }^{d}$ https://orcid.org/0000-0002-8880-1501
}

\section{RESUMEN}

Haematococcus pluvialis es una microalga que produce astaxantina, un betacaroteno y antioxidante ampliamente usado en la industria. Con el fin de obtener una mayor producción de astaxantina, se planteó como objetivo utilizar diferentes factores de estrés en un biorreactor de 5 litros a escala de laboratorio. Se cultivó la microalga en el medio RM con un pH de 6,8, temperatura $20 \pm 2 \stackrel{\circ}{ }$, aire filtrado, iluminación con lámparas blancas $20 \mathrm{~h}$ luz/4 h oscuridad, irradiancia 75 luxes y el uso de diferentes concentraciones de acetato de sodio y cloruro de sodio. Se determinó crecimiento celular, cambios morfológicos y cuantificación de astaxantina y clorofila por espectrofotometría. Además, se realizó un análisis estadístico a través de ANOVA (95\%). Utilizando 0,299 mg/L de acetato de sodio se obtuvo un crecimiento celular de $2,0 \times 10^{4}$ $\mathrm{cel} / \mathrm{mL}$ y una concentración de astaxantina de 2,530

Citation: Lancheroz-Díaz, A. G., Díaz-Barrera, L. E. y Camacho-Kumern, J. E. (2021). Producción de astaxantina en Haematococcus pluvialis bajo factores de estrés salino utilizando un biorreactor de 5 L. Mutis, 11 (2), 6483. https://doi.org/10.21789/22561498.1780

Recibido: 9 de febrero de 2021. Aceptado: 1 de junio de 2021.

Copyright: @2021. Lancheroz-Díaz, A. G., Díaz-Barrera, L. E. y CamachoKumern, J. E.. (2021). This is an open-access article, which permits unrestricted use, distributions and reproduction in any medium, provided the original author and source are credited.

Competing Interests: The authors have no conflict of interest. $\mu \mathrm{g} / \mathrm{mL}$, mientras que con $1,6 \mathrm{mg} / \mathrm{L}$ de acetato de sodio el crecimiento celular fue de $3,5 \times 10^{4} \mathrm{cel} / \mathrm{mL}$ y la concentración de astaxantina de $1,9 \mu \mathrm{g} / \mathrm{ml}$. El tratamiento que recibió $1,6 \mathrm{~g} / \mathrm{L}$ de acetato de sodio y 6,4 $\mathrm{g} / \mathrm{L}$ de cloruro de sodio presentó la mayor producción de astaxantina $(7,3 \mu \mathrm{g} / \mathrm{ml})$. Por su parte, el tratamiento con acetato de sodio $0,320 \mathrm{~g} / \mathrm{L}+$ cloruro de sodio $1,28 \mathrm{~g} / \mathrm{L}$ presentó el mayor crecimiento celular $(1,64$ x $10^{5}$ células $\left./ \mathrm{ml}\right)$. Esta investigación destaca la importancia de cultivar inicialmente la microalga utilizando el biorreactor Tecferm de 5 litros, para luego, una vez 
finalizada su fase exponencial, someterla a factores de estrés con acetato de sodio y cloruro de sodio, con lo cual se logra una mayor producción de astaxantina $(7,325 \mu \mathrm{g} / \mathrm{ml})$.

Palabras clave: microalga, crecimiento celular, biorreactor, acetato de sodio, astaxantina.

\section{ABSTRACT}

Haematococcus pluvialis is a type of microalgae that produces astaxanthin, a beta-carotene and antioxidant widely used for industrial purposes. Therefore, the objective of this research was to test different stress factors in a 5 -liter laboratory-scale bioreactor in order to obtain a higher production of astaxanthin. The microalgae were cul-

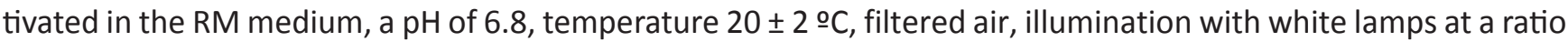
of $20 \mathrm{~h} \mathrm{light/4h} \mathrm{darkness,} \mathrm{irradiance} 75$ luxes, and different concentrations of sodium acetate and chloride of sodium. Cell growth, morphological changes, and the quantification of astaxanthin and chlorophyll were determined by spectrophotometry. Statistical analysis was performed through ANOVA (95\%). A cell growth of $2.0 \times 10^{4} \mathrm{Cel} /$ $\mathrm{mL}$ and an astaxanthin concentration of $2.530 \mu \mathrm{g} / \mathrm{mL}$ were obtained using $0.299 \mathrm{mg} / \mathrm{L}$ of sodium acetate. Using $1.6 \mathrm{mg} / \mathrm{L}$ of sodium acetate cell growth was $3.5 \times 10^{4} \mathrm{Cel} / \mathrm{mL}$ and astaxanthin concentration reached a value of $1.9 \mu \mathrm{g} / \mathrm{mL}$. The treatment in which $1.6 \mathrm{~g} \mathrm{~L}$ of sodium acetate and $6.4 \mathrm{~g} / \mathrm{L}$ of sodium chloride were added showed the highest astaxanthin production $(7.3 \mu \mathrm{g} / \mathrm{ml})$. In addition, the treatment with $0.320 \mathrm{~g} / \mathrm{L}$ sodium acetate +1.28 $\mathrm{g} / \mathrm{L}$ sodium chloride showed the highest cell growth $\left(1.64 \times 10^{5} \mathrm{cell} / \mathrm{ml}\right)$. This research highlights the importance of initially cultivating the microalgae using the 5 -liter Tecferm bioreactor and -after its exponential phase- subjecting it to stress factors with sodium acetate and sodium chloride, which allows achieving a high production of astaxanthin, estimated at $7.325 \mathrm{\mu g} / \mathrm{ml}$.

Keywords: Microalgae, cell growth, bioreactor, sodium acetate, astaxanthin.

\section{INTRODUCCIÓN}

Las microalgas son fuente de un gran número de compuestos bioactivos de interés industrial, como los carotenoides, que se utilizan como colorantes naturales en alimentación animal y humana, así como en la industria farmacéutica, cosmética y en la acuicultura. Además, las microalgas han sido consideradas como agentes efectivos en la prevención de diversas enfermedades debido a su capacidad antioxidante, inmunorreguladora, antiinflamatoria y anticancerígena (Shah et al., 2016).

El cultivo de microalgas también tiene la capacidad de metabolizar los nutrientes del medio en donde habitan, por lo cual estas son utilizadas para la biorremediación de aguas residuales producto de la actividad industrial, doméstica y la explotación agropecuaria, que no deben ser vertidas directamente a los cuerpos de agua debido a los problemas sanitarios que puedan generar. En este contexto, la implementación de métodos microbiológicos podría dar un nuevo enfoque a las tecnologías de reducción utilizadas actualmente (Vásquez-Perea et al., 2014).
El alga unicelular $H$. pluvialis ha sido estudiada exhaustivamente debido a su capacidad para acumular astaxantina y otros carotenoides relacionados. La acumulación de este carotenoide en la microalga se encuentra relacionada con la evolución de diferentes etapas de la célula vegetativa a la aplanospora en el ciclo de la microalga, aunque esta transición solo se da cuando esta ha sido sometida a diferentes condiciones de estrés (Shah et al., 2016). Actualmente, se conocen diferentes condiciones de estrés como la deficiencia de nutrientes tales como el nitrógeno (Gómez et al., 2019; Ma et al., 2018; Tocquin et al., 2012 ), la intensidad de la luz (Lv et al., 2016), colores de luz (Xi et al., 2016), alta salinidad (Lababpour \& Lee, 2006), $\mathrm{pH}$ y la presencia de nutrientes orgánicos como acetato de sodio o la combinación cloruro de sodio/acetato de sodio, aumentando el contenido total de carotenoides y el contenido total de astaxantina (Pan-utai et al., 2017; Vidhyavathi et al., 2009). El acetato de sodio ha demostrado ser una fuente importante de carbono para la microalga, mejorando su crecimiento y carotenogénesis, debido a que afecta la ruta de la fotosíntesis (He et al., 2018) y aumenta la expresión del gen BKT, produciendo así mayor cantidad de astaxantina, 
como lo reportan Wan et al. (2014), quienes utilizaron para el cultivo de la microalga $H$. pluvialis y la producción de astaxantina un fotobiorreactor de 10 Litros con medio NIES-C, usando una concentración $10 \mathrm{mM}$ de acetato de sodio como fuente de carbono, luz continua con irradiancia de $25 \mu \mathrm{mol} \mathrm{m} \mathrm{m}^{-2} \mathrm{~s}^{-1}$, temperatura de 25 으, $\mathrm{CO}_{2} 4 \%$ y pH 7,5, obteniendo una producción de astaxantina de 65,8 mg y una producción de biomasa de 3,7 mg durante 12 días de experimentación. Así mismo, Park et al. (2014) reportaron un aumento de la producción de astaxantina utilizando un cultivo mixotrófico combinando acetato de sodio y alta irradiancia, obteniendo una producción de astaxantina de $602 \mathrm{mg} / \mathrm{L}$.

La realización de esta investigación pretende aprovechar los avances de la ciencia y la tecnología basados en la utilización de las propiedades de los organismos, en particular en los niveles celular y subcelular, para generar y adaptar tecnologías que permitan obtener compuestos bioactivos a través de bioprocesos. A partir de ello, una estrategia promisoria para mejorar la producción de astaxantina en $\mathrm{H}$. pluvialis es el estudio de las rutas metabólicas y su regulación con el fin de optimizar las condiciones de crecimiento, desarrollo y producción, puesto que la utilización del $H$. pluvialis presenta ciertas dificultades durante la etapa de cultivo y la obtención del pigmento en cantidades de interés como resultado de su complejo ciclo celular. Al respecto, uno de los principales inconvenientes es que se trata de un producto del metabolismo secundario, por lo que durante el crecimiento activo de la microalga no se produce síntesis de astaxantina, lo cual ocurre solo cuando cesa la división celular, se inicia su síntesis y este carotenoide se acumula en grandes cantidades.

El H. pluvialis también reporta tasas de crecimiento bajas, lo que debilita sus posibilidades de uso como fuente natural del pigmento, además de ser altamente susceptible a la contaminación. Estas características requieren cultivos en sistemas cerrados, los cuales ofrecen ventajas como mejor control del cultivo, protección de la contaminación ambiental y producción de gran cantidad de biomasa, así como el desarrollo de un medio de cultivo óptimo para su crecimiento, considerando que el uso de una adecuada tecnología de cultivo incrementa la producción de biomasa hasta niveles óptimos para la producción del pigmento. De igual forma, un mayor entendimiento de las bases moleculares de la relación condiciones de estrés-inducción-acumulación de astaxantina en $H$. pluvialis podría ser útil para aumentar la productividad de este compuesto.

Por lo anterior, la presente investigación busca determinar un método adecuado y óptimo para la producción de astaxantina, puesto que actualmente esta se sintetiza químicamente y reporta un alto costo de producción, cercano a USD 2.500 por kilogramo (Richmond \& Hu, 2013; Shah et al., 2016; Sugawara \& Maoka, 2021), además de haber sido prohibida en el mercado por la Administración de Medicamentos y Alimentos de Estados Unidos (FDA, en inglés) como consecuencia de su baja biodisponibilidad y seguridad. Estas preocupaciones se deben principalmente a la estereoquímica diferente y el potencial arrastre de los intermedios de síntesis, lo cual hace que la astaxantina natural de $H$. pluvialis sea una opción viable y de buena calidad frente a la utilización de su forma química y de otros microorganismos capaces de producirla.

Teniendo en cuenta la capacidad de $H$. pluvialis para producir y acumular gran cantidad de astaxantina, así como la necesidad de determinar las condiciones óptimas para aumentar su producción, el objetivo del presente trabajo es determinar el efecto del estrés salino utilizando acetato de sodio y cloruro de sodio, combinado con alta irradiancia, con el fin de seleccionar condiciones de proceso. Para ello, se emplearon biorreactores de $500 \mathrm{~mL}$ y se realizó el escalamiento del cultivo en un biorreactor Tecferm de 5 litros, usando los factores de estrés acetato de sodio y alta irradiancia. Adicionalmente, se llevó a cabo la cuantificación del crecimiento celular, la caracterización morfológica y la cuantificación de astaxantina y de clorofila.

\section{MATERIALES Y MÉTODOS}

\section{Microorganismo y cultivo}

La microalga $H$. pluvialis fue obtenida de la colección de cultivos de algas de la Universidad de Texas (UTEX 2505), siendo suministrada por la facultad de Ingeniería de la Universidad de La Sabana. La cepa se mantuvo en medio sólido y líquido Mes-Volvox (sugerido por la UTEX) a baja irradiancia y una temperatura entre 15 y $20 \stackrel{\circ}{ }$ (UTEX, 2019).

El cultivo se realizó en medio de cultivo Mes-Volvox, el cual consistía de $\mathrm{Ca}\left(\mathrm{NO}_{3}\right)_{2} \cdot 4 \mathrm{H}_{2} \mathrm{O} 11,8 \mathrm{~g} 100 \mathrm{~mL}^{-1}$, 
$\mathrm{MgSO}_{4} .7 \mathrm{H}_{2} \mathrm{O} 4 \mathrm{~g} 100 \mathrm{~mL}^{-1}$, Na2glicerofosfato. $5 \mathrm{H}_{2} \mathrm{O}$ $0,05 \mathrm{~g} \mathrm{~L}^{-1}, \mathrm{KCl} 0,05 \mathrm{~g} / \mathrm{L}$, MES 1,95 $\mathrm{g} \mathrm{L}^{-1}$, solución de metales PIV $6 \mathrm{ml} \mathrm{L}^{-1}, \mathrm{NH}_{4} \mathrm{Cl} 0,026 \mathrm{~g} \mathrm{~L}^{-1}$, vitamina B12 $1 \mathrm{ml} \mathrm{L}^{-1}$, HEPES y biotina $1 \mathrm{ml} \mathrm{L}^{-1}$, ajustado a $\mathrm{pH}$ de 6,7 , luz blanca provista por lámparas fluorescentes (Tlt 20w/54RS marca Philips) con una irradiancia de 75 lux, fotoperíodo de 18 horas de luz y 6 horas de oscuridad, temperatura de $25 \stackrel{\circ}{ } \mathrm{C}$, aire filtrado y agitación manual de 10 segundos al día.

El cultivo se monitoreo por medio de microscopía en cámara de Neubauer, donde cada tercer día se realizaba conteo y se evaluaban parámetros como color (pigmento), morfología y viabilidad celular.

\section{Efecto de estrés salino sobre la producción de astaxantina}

\section{Preparación del cultivo}

El cultivo de $H$. pluvialis se realizó en sistema batch por triplicado para cada tratamiento a ensayar utilizando el medio de cultivo $\mathrm{RM}$, el cual consistió de $\mathrm{NaNO}_{3} 300 \mathrm{mg} \mathrm{L}^{-1}, \mathrm{~K}_{2} \mathrm{HPO}_{4} 80 \mathrm{mg} \mathrm{L}^{-1}, \mathrm{KH}_{2} \mathrm{PO}_{4} 60$ $\mathrm{mg} \mathrm{L}^{-1}, \mathrm{MgSO}_{4} .7 \mathrm{H} 2 \mathrm{O} 10 \mathrm{mg} \mathrm{L}^{-1}, \mathrm{CaCl}_{2} \cdot 2 \mathrm{H}_{2} \mathrm{O} 58,5 \mathrm{mg}$ $\mathrm{L}^{-1}$, EDTA 7,5, mg L-1, $\mathrm{NaCl} 20 \mathrm{mg} \mathrm{L}^{-1}, \mathrm{H}_{3} \mathrm{BO}_{3} 0,3 \mathrm{mg}$ $\mathrm{L}^{-1}, \mathrm{MnSO}_{4} \cdot \mathrm{H}_{2} \mathrm{O} 1,5 \mathrm{mg} \mathrm{L}^{-1}, \mathrm{ZnSO}_{4} \cdot 7 \mathrm{H}_{2} \mathrm{O} 0,1 \mathrm{mg} \mathrm{L}^{-1}$, (NH4)6Mo7O24.4H2O 0,3 mg L-1, CuSO4.5H2O 0,08

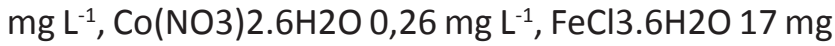
$\mathrm{L}^{-1}$, ajustado a un pH de 6,7 (Imamoglu et al., 2007).

Los tratamientos a ensayar fueron medio RM utilizado como control del estudio (tratamiento 1), con adiciones de $0,18 \mathrm{~g} / \mathrm{L}$ de acetato de sodio desde el inicio y $0,72 \mathrm{~g} / \mathrm{L}$ de cloruro de sodio (tratamiento 2 ); $1,6 \mathrm{~g} / \mathrm{L}$ de acetato de sodio desde el inicio y $6,4 \mathrm{~g} / \mathrm{L}$ de cloruro de sodio (tratamiento 3 ) (la adición de cloruro de sodio en los tratamientos 2 y 3 se realizó en el día 15 del cultivo; $0,18 \mathrm{~g} / \mathrm{L}$ de acetato de sodio y $0,72 \mathrm{~g} / \mathrm{L}$ de cloruro de sodio (tratamiento 4); $1,6 \mathrm{~g} / \mathrm{L}$ de acetato de sodio + 6,4 g/L de cloruro de sodio (tratamiento 5); y 0,320 g/L acetato de sodio $+1,28 \mathrm{~g} / \mathrm{L}$ de cloruro de sodio (tratamiento 6). La adición de las sales en los tratamientos 4 , 5 y 6 , se realizó en el día 15 del cultivo. El medio estéril con el pH ajustado se adicionó en biorreactores de 500 $\mathrm{ml}$ hasta un volumen de $350 \mathrm{ml}$. Los biorreactores se sellaron para garantizar esterilidad (Rodríguez, 2019).

Se procedió a adicionar el inóculo de la microalga con una concentración de $1 \times 10^{4}$ células $\mathrm{mL}^{-1}$ a cada biorreactor. Se realizó el cultivo bajo las siguientes condiciones: $\mathrm{pH}$ 6,7, ciclo luz/oscuridad 20:4 h, temperatura $20 \stackrel{\circ}{ } \mathrm{C}$, agitación continua, aire filtrado, iluminación con lámparas fluorescentes blancas ( $\mathrm{Tlt}$ 20w/54RS marca Philips) y una irradiancia de 75 lux.

Se realizó también el cultivo de H. pluvialis en el biorreactor Tecferm a escala de laboratorio de 5 litros (figura 1) en sistema batch en el medio RM, utilizando $2 \mathrm{~L}$ del medio de cultivo $\mathrm{RM}, \mathrm{pH} 6,7$, ciclo luz/oscuridad 20:4 h, temperatura $20 \stackrel{\circ}{\circ}$, agitación 100 rpm, aire filtrado, iluminación con lámparas fluorescentes blancas (TIt 20w/54RS marca Philips) y una irradiancia de 75 lux. Los tratamientos realizados utilizaron una concentración de 0,299 mg/L de acetato de sodio en el medio RM, tomando como referencia un tratamiento previo donde se utilizaron $0,310 \mathrm{mg} / \mathrm{L}$ de acetato de sodio combinado con una irradiancia a $140 \mu \mathrm{E} / \mathrm{m}^{2} \mathrm{~s}$ en medio $\mathrm{RM}$, obteniendo $8,3 \mu \mathrm{g} / \mathrm{ml}$ de astaxantina (Giannelli et al., 2015; Niño-Castillo \& RodríguezRivera, 2015) y 1, $6 \mathrm{mg} / \mathrm{L}$ de acetato de sodio en el medio RM bajo las condiciones de trabajo previamente establecidas (García, 2018).

La toma de muestras se realizó cada tres días en forma aséptica. La conservación de las muestras se realizó en solución salina (1:9) en una proporción 1:1, tomando $1,0 \mathrm{~mL}$ para realizar control del cultivo (conteo celular, viabilidad, morfología y registro fotográfico). El resto de la muestra se utilizó para medición de $\mathrm{pH}$. Adicionalmente, se tomaron $10 \mathrm{~mL}$ para cuantificación de pigmentos. El tiempo de estudio fue de 36 días.

Figura 1. Biorreactor Tecferm

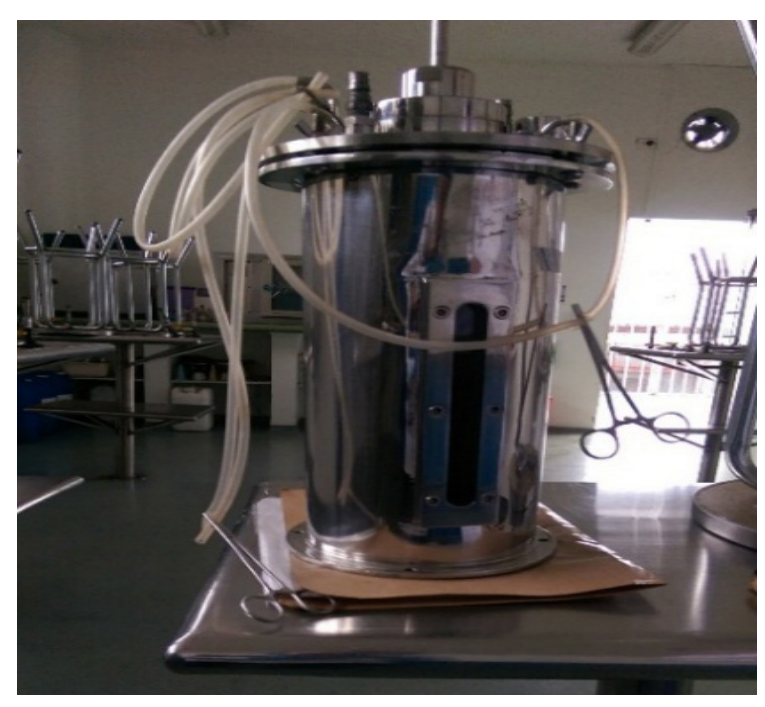

Fuente: tomado de García (2018). 


\section{Determinación de concentración de clorofila y astaxantina}

Las muestras fueron centrifugadas a $12.000 \mathrm{rpm}$ durante 5 minutos. Posteriormente, se retiró el sobrenadante (medio de cultivo). Al paquete celular se le adicionó $1 \mathrm{~mL}$ de metanol al $90 \%$ para luego ser calentado durante $10 \mathrm{~min}$ a $60 \stackrel{\circ}{\mathrm{C}}$ en baño serológico, tras lo cual fue centrifugado nuevamente a 12.000 rpm durante 5 minutos (APHA, 1992).

Para la cuantificación de clorofila y astaxantina se realizó la curva de calibración con patrones de referencia, llevando a cabo la lectura espectrofotométrica en el equipo Thermo Scientific Evolution 201, a una longitud de onda de $667 \mathrm{~nm}$ para clorofila y $477 \mathrm{~nm}$ para astaxantina. Las concentraciones se expresan en $\mu \mathrm{g} / \mathrm{ml}$.

\section{Crecimiento de $\boldsymbol{H}$. pluvialis}

Se realizó conteo celular en cámara de Neubauer por triplicado. Se realizó curva de crecimiento a partir de los resultados. Las tendencias de crecimiento fueron ajustadas al modelo logístico mediante transformación de los valores de $\mathrm{Y}$, cuyo logaritmo fue calculado en base 10 para la obtención de log vs tiempo.

\section{Análisis estadístico}

Los experimentos se realizaron por triplicado para cada tratamiento ensayado. Se realizó un análisis de varianza ANOVA (95\%) para determinar diferencias significativas entre tratamientos, donde los valores de $P<0,05$ fueron considerados estadísticamente significativos. Para el análisis estadístico se utilizó el programa Excel 2016.

\section{RESULTADOS}

El tratamiento con $0,299 \mathrm{mg} / \mathrm{L}$ en el medio RM y el uso del biorreactor Tecferm de 5 litros permitió obtener un recuento de inicial de $1,0 \times 10^{4} \mathrm{cel} / \mathrm{mL}$ y un recuento final del $1 \times 10^{3} \mathrm{cel} / \mathrm{mL}$ durante los 34 días del estudio. El pH presentó fluctuaciones entre 6,7 y 7,5, siendo cercano a un nivel neutro.

El recuento celular obtenido con el tratamieno de $0,299 \mathrm{mg} / \mathrm{L}$ de acetato de sodio indica que la microalga presenta crecimiento exponencial hasta el día 13, con un recuento celular de $2,0 \times 10^{4} \mathrm{cel} / \mathrm{mL}$ hasta el día 20, cuando este empieza a disminuir hasta el día 34 , en el que se reporta un recuento de $1 \times 10^{3} \mathrm{cel} / \mathrm{mL}$ (figuras 2 y 4 ).

Con respecto al recuento celular obtenido con el tratamieno de 1,6 mg/L de acetato de sodio, se observó de nuevo que la microalga presenta un crecimiento exponencial hasta el día 13, alcanzando un recuento de 2,5 $\times 10^{4} \mathrm{cel} / \mathrm{mL}$, para luego iniciar una disminución que se prolonga hasta el día 20 . Finalmente, el día 27 reporta un recuento de $1,7 \times 10^{4} \mathrm{cel} / \mathrm{mL}$. En el día 34 se obtiene un aumento del recuento celular de 3,5 x 104 $\mathrm{cel} / \mathrm{mL}$, valor superior al registrado el día 13 , momento en el que finaliza la fase exponencial de la microalga (figuras 3 y 4). El medio de cultivo con mayor velocidad específica de crecimiento fue el RM con concentración de acetato de sodio $0,299 \mathrm{mg} / \mathrm{L}$, con una velocidad de crecimiento de 0,029 células/día (tabla 1 ).

Figura 2. Curva crecimiento celular con $0,299 \mathrm{mg} / \mathrm{L}$ de acetato de sodio

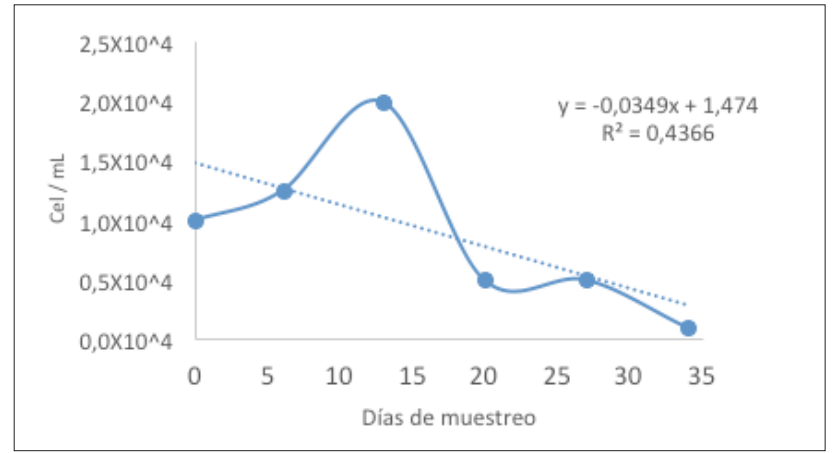

Fuente: García (2018).

Figura 3. Curva crecimiento celular con $1,6 \mathrm{mg} / \mathrm{L}$ de acetato de sodio

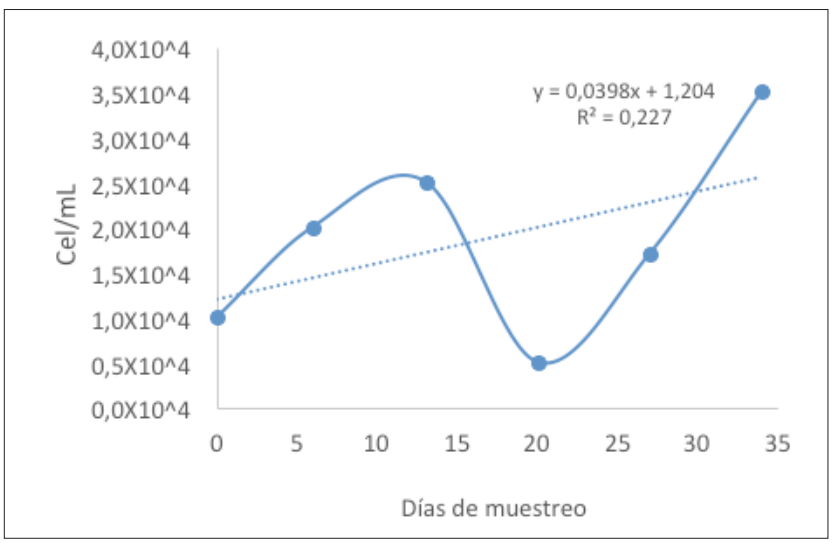

Fuente: García (2018). 
Figura 4. Curva crecimiento celular con acetato de sodio

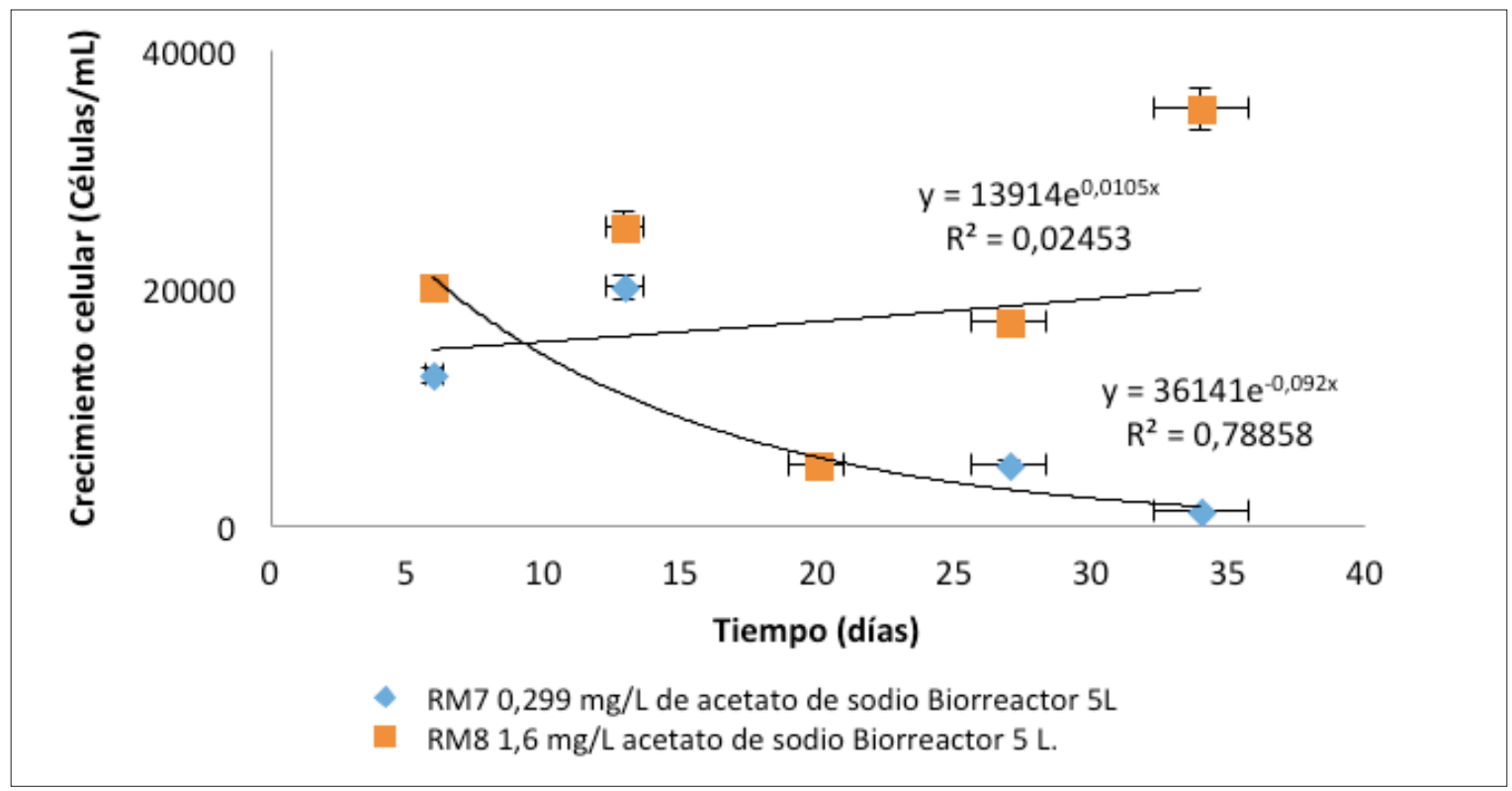

Fuente: elaboración propia.

Tabla 1. Matriz de coeficientes del modelo logístico ajustado para los diferentes tratamientos

\begin{tabular}{|c|c|c|c|c|c|}
\hline Medio de cultivo & Número de datos & Dato mínimo & Dato máximo & $\begin{array}{c}\text { Velocidad de creci- } \\
\text { miento }\end{array}$ & $\begin{array}{c}\text { Coeficiente de } \\
\text { determinación }\end{array}$ \\
\hline $\begin{array}{c}\text { RM y acetato 0,299 } \\
\mathrm{mg} / \mathrm{L}\end{array}$ & 6 & 4,204 & 4,300 & $0,029 \mathrm{cel} / \mathrm{día}$ & 79 \\
\hline $\begin{array}{c}\mathrm{RM} \text { y acetato 1,6 } \\
\mathrm{mg} / \mathrm{L}\end{array}$ & 6 & 4,301 & 4,540 & $0,014 \mathrm{cel} / \mathrm{día}$ & 49 \\
\hline
\end{tabular}

Fuente: García (2018).

El ANOVA (95\%) estableció que no existen diferencias significativas entre los tratamientos ensayados $(P=0,795 ; g l=1 ; F=0,071)$. Sin embargo, el tratamiento que brinda mejores resultados es aquel en el que se utilizaron $0,299 \mathrm{mg} / \mathrm{L}$ de acetato de sodio, puesto que con esta concentración se obtuvo un mayor crecimiento y mejor velocidad, mejorando así el crecimiento de la microalga y posiblemente generando una mayor acumulación de astaxantina. Esta concentración también presentó un mejor ajuste al modelo logístico de crecimiento.

En cuanto a las concentraciones de astaxantina y clorofila (expresadas en $\mu \mathrm{g} / \mathrm{mL}$ ), el tratamiento con $0,299 \mathrm{mg} / \mathrm{L}$ de acetato de sodio (figura 5 y 7a) presenta concentraciones de $28,706 \mu \mathrm{g} / \mathrm{mL}$ de clorofila y $2,530 \mu \mathrm{g} / \mathrm{mL}$ de astaxantina, comportamiento que se correlaciona con el recuento celular obtenido. 
Figura 5. Concentraciones de clorofila y astaxantina durante el montaje de $0,299 \mathrm{mg} / \mathrm{L}$

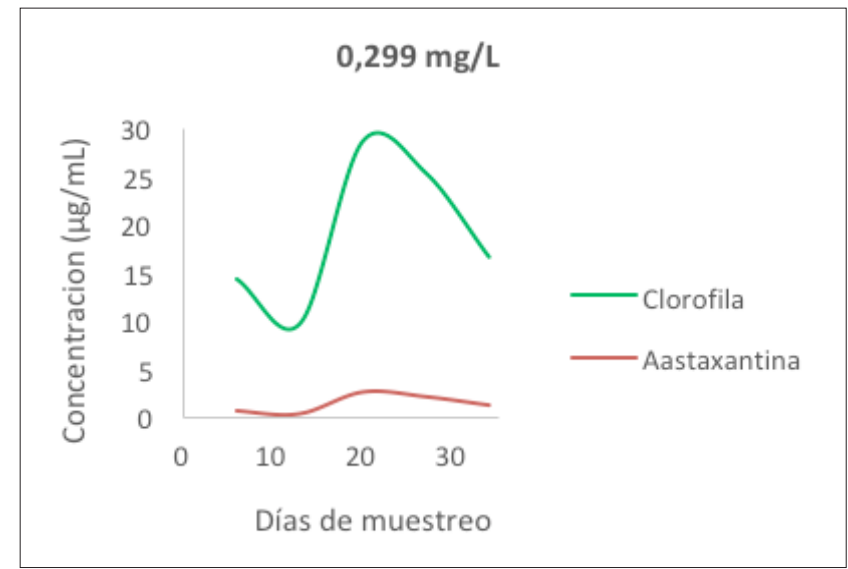

Fuente: García (2018).
Figura 6. Concentraciones de clorofila y astaxantina durante el montaje de $1,6 \mathrm{mg} / \mathrm{L}$

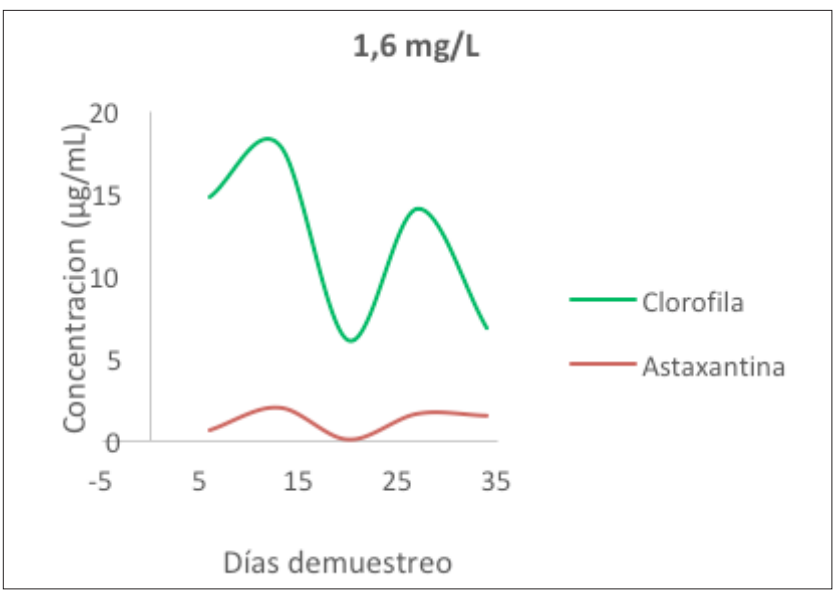

Fuente: García (2018).

Figura 7. Concentraciones de clorofila (A) y astaxantina (B)

A.

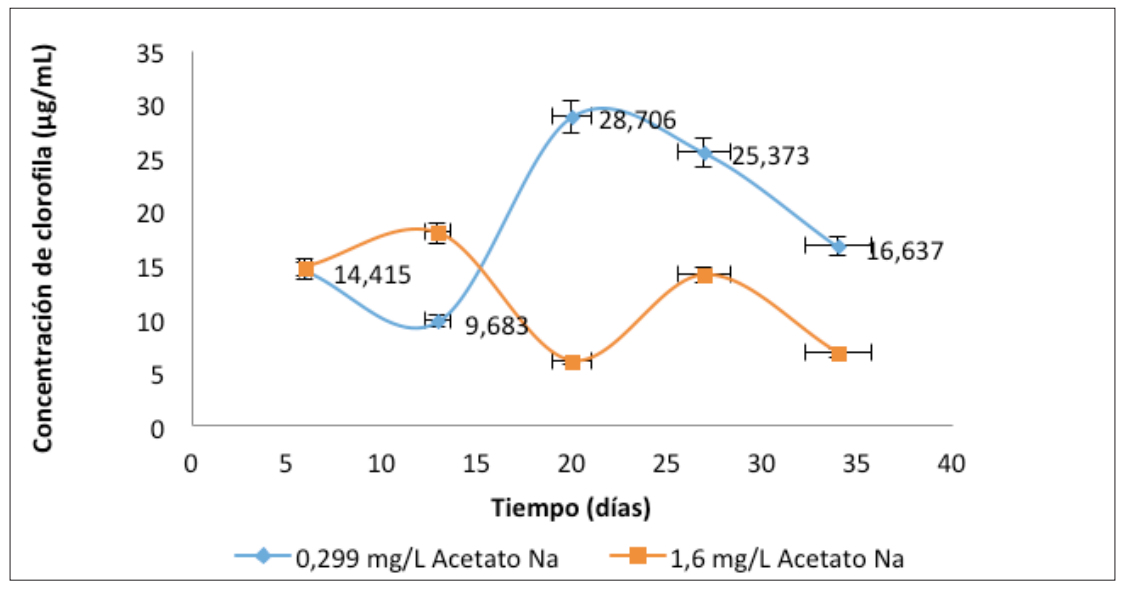

B.

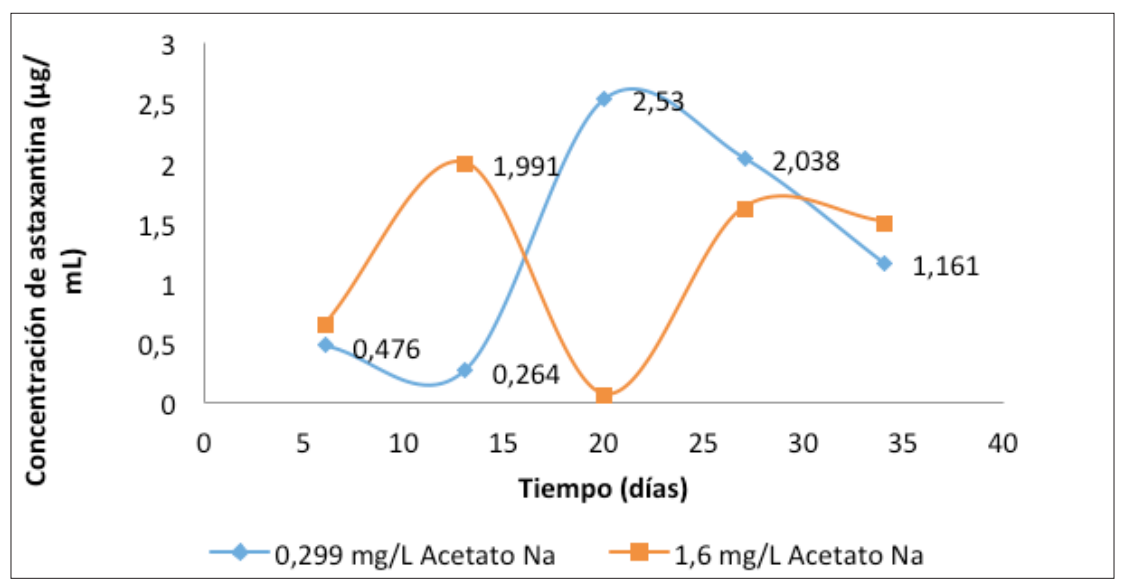

Fuente: elaboración propia. 
De otro lado, en el tratamiento con 1,6 mg/L de acetato de sodio (figuras 5 y $7 \mathrm{~A}-\mathrm{B}$ ) se encontró mayor concentración de clorofila que de astaxantina, ambas presentando su pico máximo en el día 13, las cuales reportaron concentraciones de $17,902 \mu \mathrm{g} / \mathrm{mL}$ y 1,991 $\mu \mathrm{g} / \mathrm{mL}$, respectivamente, comportamiento que se correlaciona con el recuento celular. El ANOVA (95\%) estableció que no existen diferencias significativas entre los tratamientos ensayados para la concentración de clorofila $(P=1 ; g l=1 ; F=0)$ y astaxantina
$(P=0,820 ; g l=1 ; F=0,054)$. Sin embargo, se observa que con la concentración de $0,299 \mathrm{mg} / \mathrm{L}$ de acetato de sodio se obtiene un incremento de $21 \%$ en la cantidad de astaxantina, en comparación con el tratamiento con $1,6 \mathrm{mg} / \mathrm{L}$.

Durante cada montaje se llevó un registro fotográfico microscópico con el fin de evaluar la morfología de la microalga desde sus formas vegetativas hasta sus formas enquistadas (tabla 2).

Tabla 2. Registro fotográfico microscópico

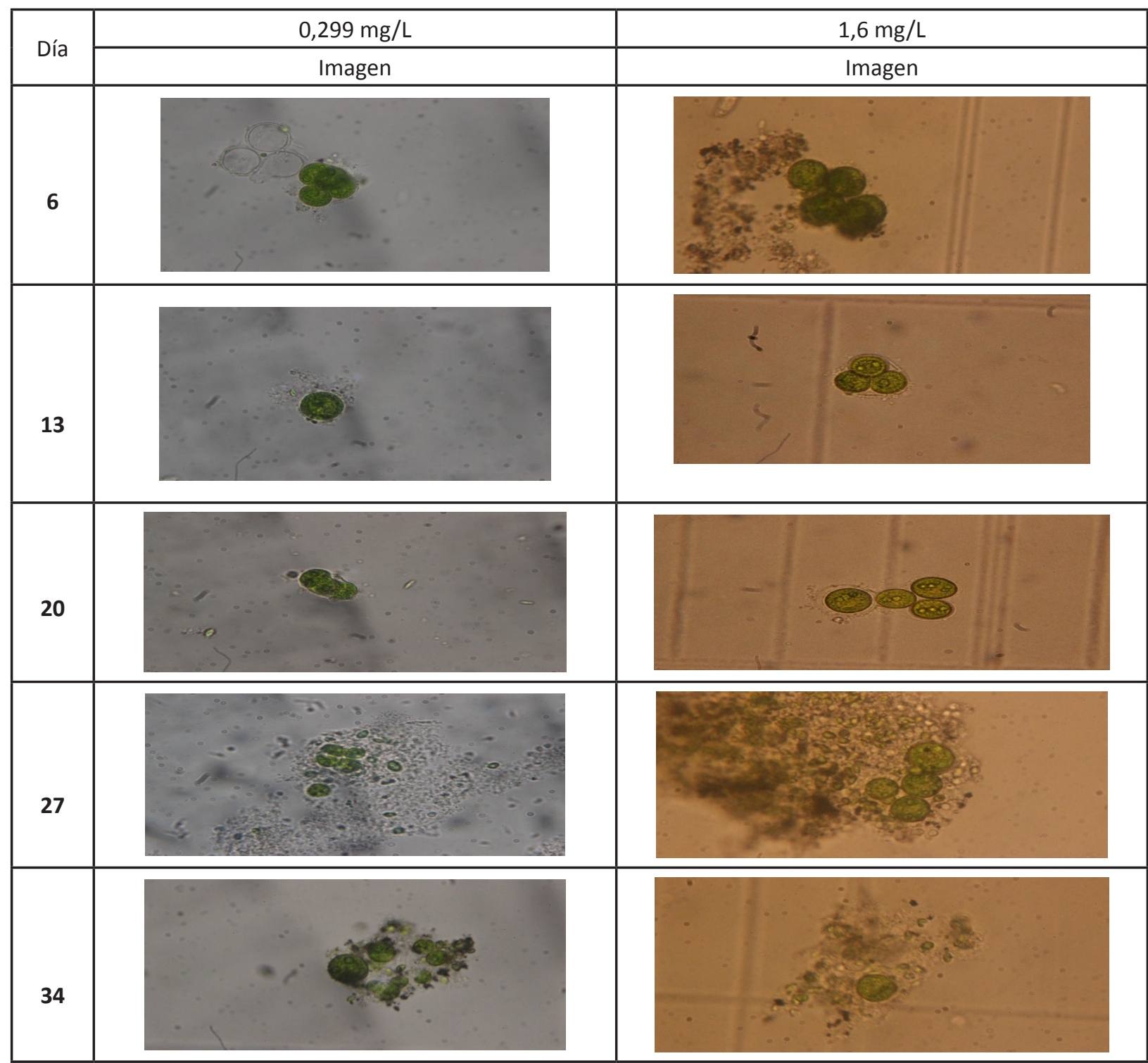


A partir del registro fotográfico de ambos tratamientos $(0,299 \mathrm{mg} / \mathrm{L}$ y $1,6 \mathrm{mg} / \mathrm{L}$ de acetato de sodio), se evidencia que estos presentaron formas celulares vegetativas, biflagelas y palmeloides sin acumulación de astaxantina. Lo anterior gracias a que - aunque sí se hallaron concentraciones de astaxantina- al momento de realizar el registro fotográfico no se pudieron observar formas quísticas con acumulación de astaxantina.
Entre los días 13 y 20 se observó una mayor cantidad de formas celulares vegetativas verdes sin flagelos debido a que el crecimiento exponencial de $H$. pluvialis ha terminado, e inicia su fase de descenso. En contraste, en los días finales de los tratamientos se observaron formas celulares quísticas debido a que los nutrientes se iban agotando, siendo las primeras un tipo de formas más resistentes (tabla 3) (Jeon et al., 2006; Wang et al., 2016).

Tabla 3. Tratamientos de $0,299 \mathrm{mg} / \mathrm{L}$ y $1,6 \mathrm{mg} / \mathrm{L}$ de acetato sodio

\begin{tabular}{|c|c|c|c|c|c|}
\hline $\begin{array}{l}\text { Concentración de } \\
\text { acetato de sodio }\end{array}$ & $\begin{array}{l}\text { Recuento celular } \\
\text { (cel/mL) }\end{array}$ & $\mathrm{pH}$ & $\begin{array}{c}\text { Concentración de } \\
\text { astaxantina }(\mu \mathrm{g} / \mathrm{mL})\end{array}$ & $\begin{array}{l}\text { Concentración de } \\
\text { clorofila }(\mu \mathrm{g} / \mathrm{mL})\end{array}$ & $\begin{array}{c}\text { Velocidad de } \\
\text { crecimiento (cel/día) }\end{array}$ \\
\hline \multirow{2}{*}{$0,299 \mathrm{mg} / \mathrm{L}$} & $2,0 \times 10^{4}$ & 7,5 & 2,530 & 28,706 & \multirow{2}{*}{0,029} \\
\hline & Día 20 & Día 34 & Día 20 & Día 20 & \\
\hline \multirow{2}{*}{$1,6 \mathrm{mg} / \mathrm{L}$} & $3,5 \times 10^{4}$ & 8,6 & 1,991 & 17,902 & \multirow{2}{*}{0,014} \\
\hline & Día 34 & Día 34 & Día 13 & Día 13 & \\
\hline
\end{tabular}

Fuente: García (2018).

A continuación se presentan los resultados obtenidos de los tratamientos donde se utilizaron biorreactores de $500 \mathrm{~mL}$, encontrándose que con $0,320 \mathrm{~g} / \mathrm{L}$ de acetato de sodio y $1,28 \mathrm{~g} / \mathrm{L}$ de cloruro de sodio, adicionados desde el día 15 del estudio al medio RM (RM6), iluminación con lámparas blancas con $20 \mathrm{~h}$ luz/4 h oscuridad y 75 lux de irradiancia, se registró una velocidad de crecimiento de 1,018 cel/día. Este fue seguido por el tratamiento RM3, el cual contenía $1,6 \mathrm{~g} / \mathrm{L}$ de acetato de sodio (añadido desde el inicio), $6,4 \mathrm{~g} / \mathrm{L}$ de cloruro de sodio (agregado el día 15 del estudio) bajo las mismas condiciones de irradiancia y fotoperíodo, reportando una velocidad de crecimiento de 0,696 cel/día (figuras 8 y 9).

Figura 8. Curva de crecimiento T. RM3 Acetato de sodio 1,6 g/L + Cloruro de sodio 6,4 g/L (izquierda) y T. RM6 Acetato de sodio 0,320 g/L + Cloruro de sodio $1,28 \mathrm{~g} / \mathrm{L}$ (derecha)
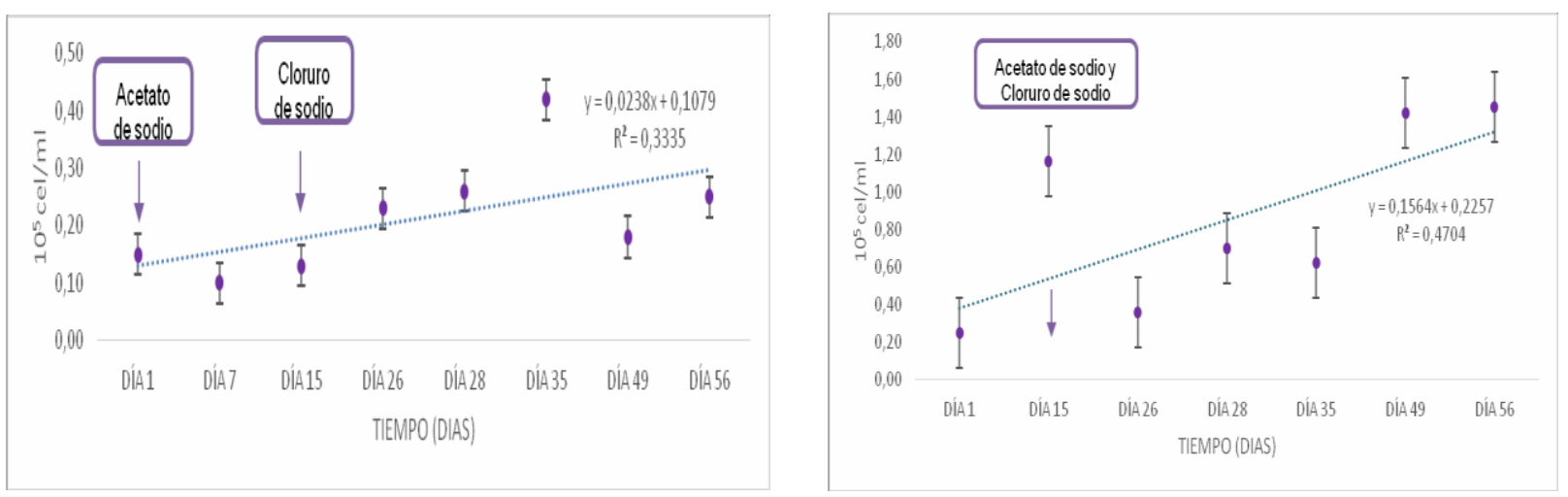

Fuente: Rodríguez (2019). 
Figura 9. Tratamientos con acetato de sodio y cloruro de sodio

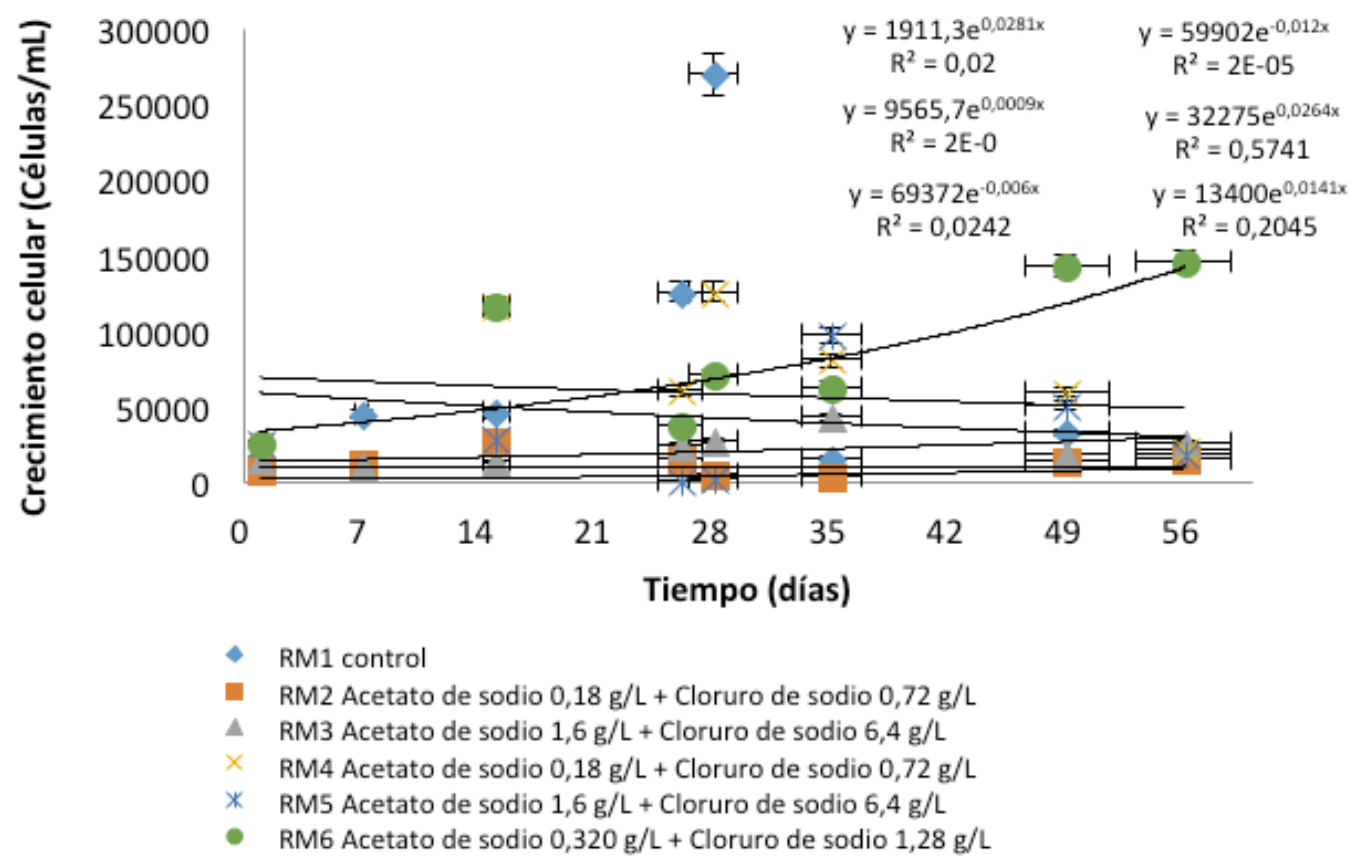

Fuente: elaboración propia.

El análisis de varianza ANOVA (95\%) estableció que existen diferencias significativas $(F=22,47 ; p=0,025$; $\mathrm{gl}=5$ ) entre los diferentes tratamientos con respecto al crecimiento celular. El tratamiento RM6 y RM4 fueron los que presentaron mayor crecimiento $(1,45$ $\times 10^{5} \mathrm{cel} / \mathrm{ml}$ y $1,25 \times 10^{5} \mathrm{cel} / \mathrm{ml}$, respectivamente). Por su parte, el control (RM1) reportó un crecimiento de $2,69 \times 10^{5} \mathrm{cel} / \mathrm{ml}$ (figuras 8 y 9).
En el estudio se observaron las dos fases que experimenta la microalga $H$. pluvialis como consecuencia de la combinación de factores de estrés: fase vegetativa y fase roja. Se observan además formas de palmella y células enquistadas (RM3), así como aplanosporas (figura 10).

Figura 10. Tratamientos de H. pluvialis (día 35)

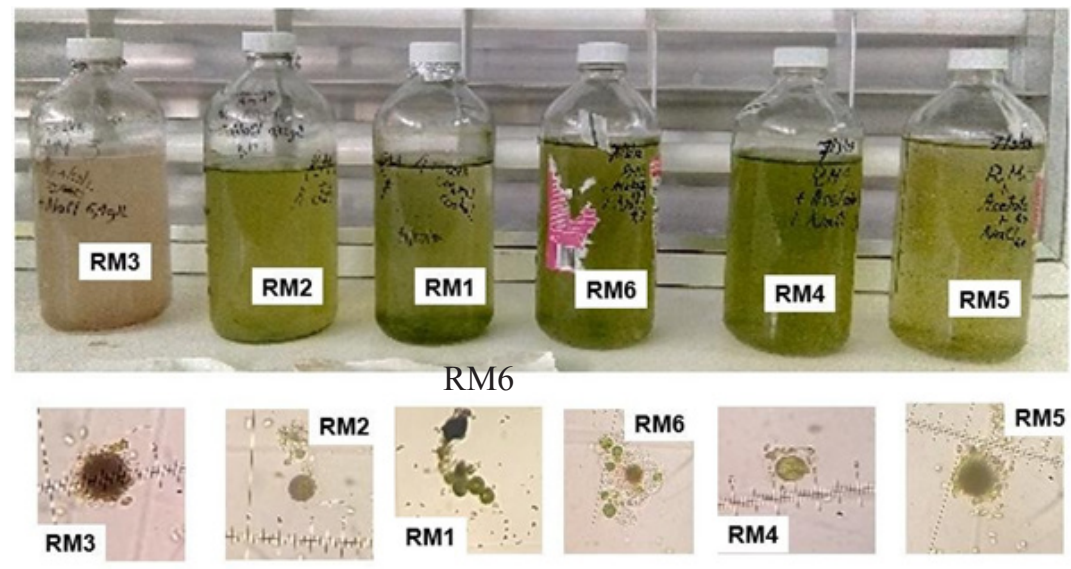

Fuente: Rodríguez (2019). 
El tratamiento que presentó la mayor concentración de clorofila fue RM6 (0,245 microgramos/L), presentándose diferencias significativas entre tratamientos $(F=4,307 ; p=0,003 ; g l=5)$. La producción de clorofila se correlaciona con el crecimiento de la microalga puesto que al aumentar la biomasa incrementa también el contenido de clorofila.

El tratamiento RM3 presentó la mayor concentración de astaxantina $(7,325 \mu \mathrm{g} / \mathrm{ml})$, utilizando una concentración de $1,6 \mathrm{~g} / \mathrm{L}$ de acetato de sodio desde el inicio del estudio y $6,4 \mathrm{~g} / \mathrm{L}$ de cloruro de sodio a partir del día 15 (figuras 11 y 12). Al analizar los tratamientos realizados, no se evidencian diferencias significativas entre estos con respecto a la producción de astaxantina $(F=1,687 ; p=0,165 ; g l=5)$. La tabla 4 presenta un resumen de los resultados obtenidos en cada tratamiento.

Figura 11. Concentración de clorofila (verde) y astaxantina (rojo) T. RM3 (acetato de sodio 1,6 g/L + cloruro de sodio 6,4 g/L) y T. RM6 (acetato de sodio $0,320 \mathrm{~g} / \mathrm{L}+$ Cloruro de sodio $1,28 \mathrm{~g} / \mathrm{L}$ )

RM3

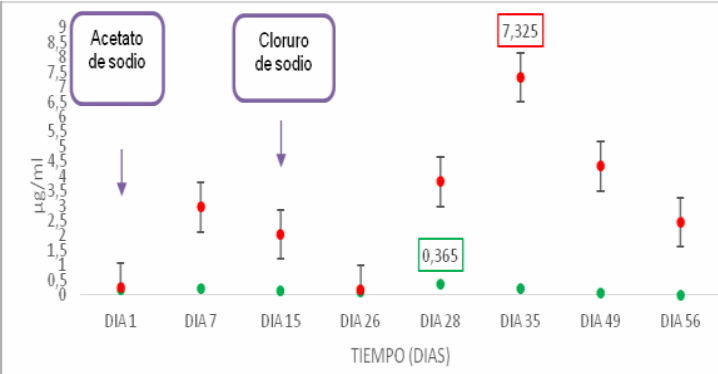

- clorofila • astaxantina

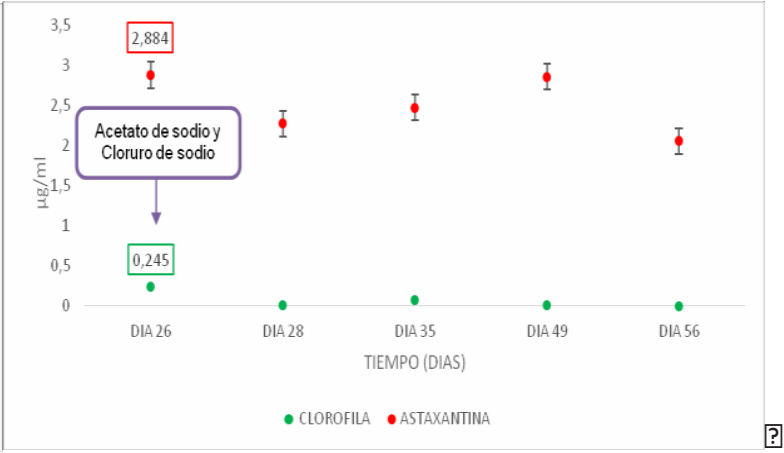

?

Fuente: Rodríguez (2019).

Figura 12. Concentración de clorofila (A) y astaxantina (B)

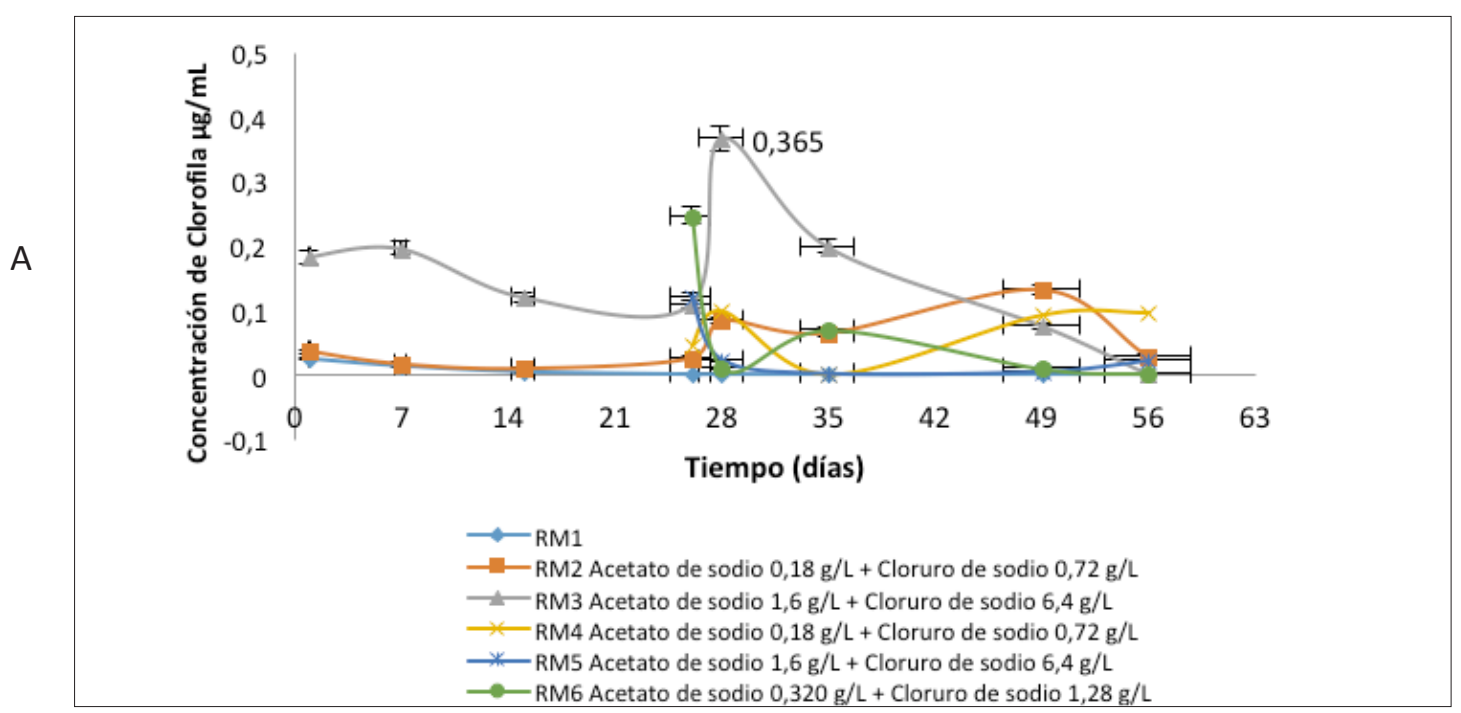




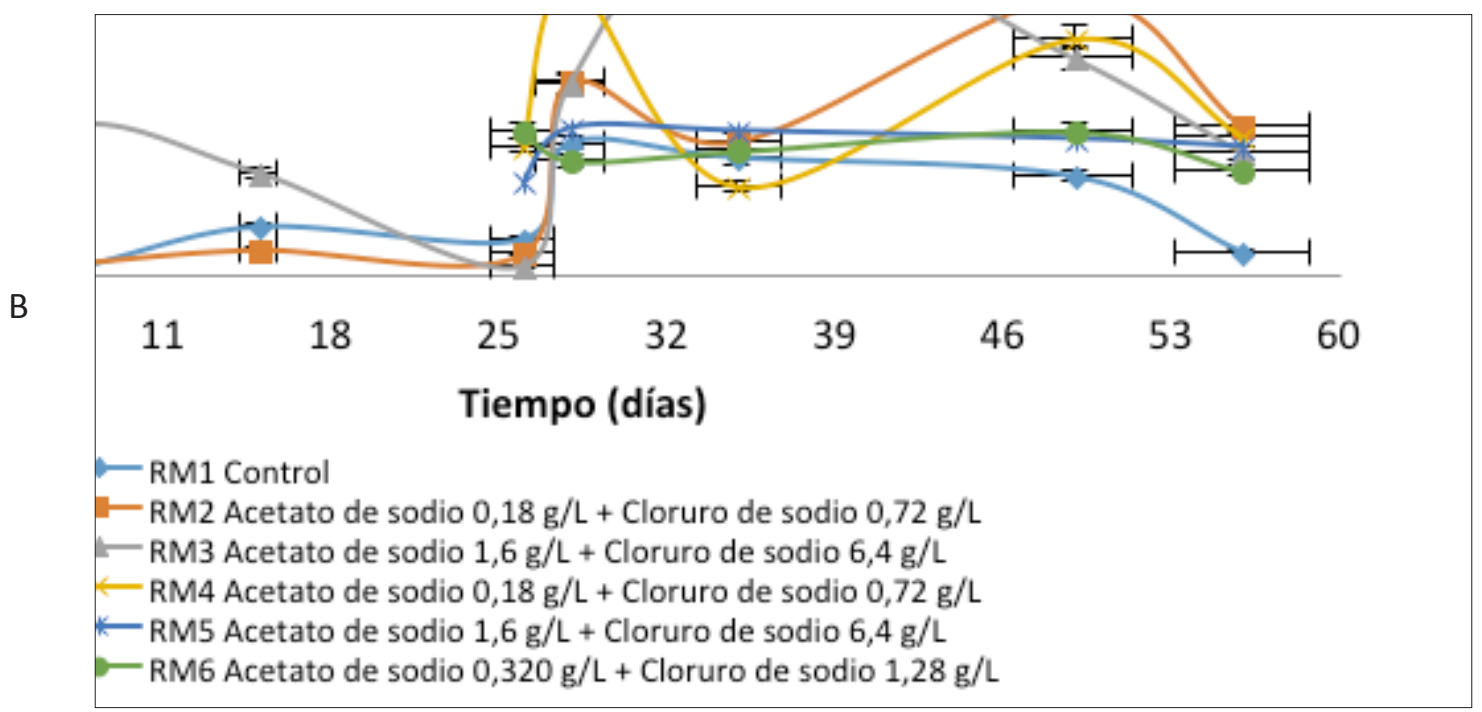

Fuente: elaboración propia.

Tabla 4. Resumen de los tratamientos realizados

\begin{tabular}{|c|c|c|c|c|c|c|c|c|}
\hline & $\begin{array}{l}\text { Crecimien- } \\
\text { to celular } \\
\text { máximo } \\
\left(\times 10^{5} \mathrm{cel} / \mathrm{ml}\right)\end{array}$ & $\begin{array}{l}\text { Día de máxi- } \\
\text { mo crecimien- } \\
\text { to celular }\end{array}$ & $P<0,05$ & $\begin{array}{c}\text { Concentración } \\
\text { máxima de } \\
\text { astaxantina } \\
(\mu \mathrm{g} / \mathrm{ml})\end{array}$ & $\begin{array}{l}\text { Día de máxi- } \\
\text { ma concen- } \\
\text { tración de } \\
\text { astaxantina }\end{array}$ & $P<0,05$ & $\begin{array}{l}\text { Concentración } \\
\text { máxima de } \\
\text { clorofila ( } \mu \mathrm{g} / \\
\mathrm{ml})\end{array}$ & $P<0,05$ \\
\hline RM1 Control & 2,69 & 28 & \multirow{6}{*}{0,025} & 2,623 & 28 & \multirow{6}{*}{0,165} & 0,024 & \multirow{6}{*}{0,003} \\
\hline RM2 & 0,27 & 15 & & 5,580 & 49 & & 0,131 & \\
\hline RM3 & 0,42 & 35 & & 7,325 & 35 & & 0,365 & \\
\hline RM4 & 1,25 & 28 & & 5,862 & 28 & & 0,098 & \\
\hline RM5 & 1,16 & 15 & & 2,936 & 28 & & 0,118 & \\
\hline RM6 & 1,45 & 56 & & 2,884 & 26 & & 0,245 & \\
\hline
\end{tabular}

ANOVA (95\%). Diferencias significativas entre tratamientos $p<0,05$.

Fuente: Rodríguez (2019). 
Al comparar los resultados de los tratamientos realizados se observa que la combinación de acetato de sodio y cloruro de sodio incrementó la producción de astaxantina en $65 \%$, en comparación con el tratamiento realizado en el biorreactor, donde se trabajó solo con acetato de sodio en una cantidad de $0,299 \mathrm{mg} / \mathrm{L}$. Esto se debe a que inicialmente el acetato de sodio es tomado como fuente de carbono para incrementar el crecimiento celular y luego es influenciado por el factor de estrés de deficiencia de nutrientes y la salinidad suministrada por el cloruro de sodio, combinados con el aumento de la irradiancia.

\section{DISCUSIÓN}

El uso de biorreactores para el escalamiento con sistemas cerrados, como el utilizado en este estudio, proporciona mejores condiciones para el crecimiento de la mayoría de microalgas, puesto que estos protegen al cultivo de la contaminación y permiten controlar de manera integral las condiciones de cultivo (Giannelli et al., 2015; Wang et al., 2013, Ramírez-Landínez, 2013), como se determinó en el cultivo realizado en el biorreactor Tecferm de 5 litros, obteniendo una biomasa adecuada de $H$. pluvialis. Además de esto, tomando como base los resultados reportados por Giannelli et al. (2015) y el trabajo de Niño-Castillo et al. (2017), se optó por utilizar el medio RM bajo las condiciones de estrés de acetato de sodio $(0,299 \mathrm{mg} / \mathrm{L}$ y $1,6 \mathrm{mg} / \mathrm{L}), \mathrm{pH} 6,8$, temperatura $20 \pm 1$ 으, fotoperíodo $20 \mathrm{~h}$ luz blanca y $4 \mathrm{~h}$ oscuridad, aire filtrado y agitación fluctuante entre 90 y $180 \mathrm{rpm}$ con el fin de aumentar el crecimiento del inoculo inicial $\left(1,0 \times 10^{4} \mathrm{cel} / \mathrm{mL}\right)$, y con ello inducir la acumulación de astaxantina en su forma quística en la microalga, como se ha observado en los estudios de Cifuentes et al. (2003) y He et al. (2018), debido a que el acetato de sodio produce una afectación de la fotosíntesis de la microalga, incrementando la producción de este carotenoide.

Autores como Gómez et al. (2019), Pan-utai et al. (2017), Vidhyavathi et al. (2009) y Ma et al. (2018) han incorporado diferentes condiciones de estrés que ayudan a la adecuada acumulación de astaxantina -como tipo, color y nivel de intensidad de luz, agitación, deficiencia de nutrientes, $\mathrm{pH}$, uso de acetato de sodio y cloruro de sodio-, reportando buenos resultados y estableciendo la importancia de combinar condiciones de estrés como la aplicación de acetato de sodio y una alta irradiancia, con lo cual se ha registrado una acumulación de astaxantina de $32,99 \mathrm{\mu g} / \mathrm{mL}$ (Tocquin et al., 2012). A partir de ello, el presente estudio utiliza el acetato de sodio como factor de estrés en diferentes concentraciones, combinado con alta intensidad de luz blanca y un fotoperíodo de 20 horas luz y 4 horas oscuridad, con lo que se observó que la concentración de 0,299 mg/L es la más adecuada para su uso en el biorreactor, permitiendo obtener un incremento de $21 \%$ en la producción de astaxantina, en comparación con la concentración de $1,6 \mathrm{mg} / \mathrm{L}$ de acetato de sodio. Esto se podría explicar teniendo en cuenta que la concentración de acetato de sodio debe ser controlada, ya que niveles inapropiados de este compuesto pueden generar la inhibición del crecimiento celular (Wan et al., 2014), lo cual posiblemente fue lo que ocurrió en este tratamiento.

El acetato de sodio es un precursor del crecimiento celular (Cifuentes et al., 2003; Giannelli et al., 2015; Wan et al., 2014), como se observa en el tratamiento con $0,299 \mathrm{mg} / \mathrm{L}$, el cual reportó un crecimiento de 2,0 $\times 10^{4} \mathrm{cel} / \mathrm{mL}$ y una velocidad de crecimiento de 0,029 cel/día, lo que contribuye a una mayor acumulación de astaxantina. Estos hallazgos son consecuentes con lo mencionado por Park et al. (2014), quienes desarrollaron sus tratamientos con un fotobiorreactor tipo APBR en sistema batch bajo las mismas condiciones del presente estudio.

Por otra parte, es posible afirmar que con las concentraciones de acetato de sodio analizadas $(0,299$ y $1,6 \mathrm{mg} / \mathrm{L}$ ) se obtiene una mejor tasa de crecimiento, con recuentos de $2,0 \times 10^{4} \mathrm{cel} / \mathrm{mL}$ y $3,5 \times 10^{4} \mathrm{cel} / \mathrm{mL}$, respectivamente. Al respecto, el trabajo de González et al. (2009) solo pudo obtener un incremento entre $1,0 \times 10^{4}$ y $1,8 \times 10^{4} \mathrm{cel} / \mathrm{ml}$, lo que nos lleva a validar que la suplementación de medios con acetato de sodio contribuye a incrementar el crecimiento celular y a la conformación de formas celulares quísticas, ya que la microalga toma el acetato de sodio como una fuente de carbono (González et al., 2009). 
Aunque se obtuvo un mayor recuento celular que en otros estudios con suplementación con acetato de sodio (Shakhmatov et al., 2018; Wan et al., 2014), se observa que los recuentos celulares entre los días 15 y 20 estuvieron en un rango de $2,0 \times 10^{4}$ a $5 \times 10^{3} \mathrm{cel} / \mathrm{mL}$ para el tratamiento con $0,299 \mathrm{mg} / \mathrm{L}$, mientras que el tratamiento con $1,6 \mathrm{mg} / \mathrm{L}$ reportó un rango entre $2,5 \times 10^{4}$ y $5 \times 10^{3} \mathrm{cel} / \mathrm{mL}$, lo cual se puede explicar de dos formas diferentes. En primer lugar, se puede afirmar que el microorganismo simplemente siguió su ciclo natural de crecimiento de aproximadamente 15 días (Jeon et al., 2006; Ranga et al., 2009; Wang et al., 2016), como lo describe la literatura. De otro lado, de acuerdo con lo establecido por Woong et al. (2006), la concentración de acetato de sodio deberá ser controlada a niveles apropiados con el fin de evitar la inhibición del crecimiento celular por acción de este compuesto. Estos autores establecen que a través de concentraciones de acetato de sodio de $50 \mathrm{mM}$ es posible obtener un rápido cambio morfológico de células vegetativas a forma quística, realizando el blanqueamiento total de las células quísticas (Wan et al., 2014), lo que nos lleva a cuestionar si la adecuada concentración de acetato de sodio es $0,310 \mathrm{mg} / \mathrm{L}$ (Giannelli et al., 2015). Teniendo en cuenta estas dos perspectivas, se estudiaron ambas concentraciones en el biorreactor Tecferm de 5 Litros a fin de establecer cuál de ellas es la más adecuada para la obtención de astaxantina (García, 2018).

Un factor a resaltar es que la mayoría de los estudios suplementados con acetato de sodio tienden a registrar una mayor producción de biomasa que de astaxantina, como se observó en el presente estudio. De esta manera, se puede hacer referencia a los autores que han descrito anteriormente que las células de $H$. pluvialis solo requieren carbono como principal nutriente en la "etapa de crecimiento", el cual puede ser suministrado diariamente por inyección de $\mathrm{CO}_{2} \mathrm{O}$ por aire filtrado (como en el presente estudio), y que una alta irradiación (fotoperíodos $20 \mathrm{~h}$ luz y $4 \mathrm{~h}$ oscuridad) proporciona mayor energía para la fijación fotosintética del carbono, lo que conduce a una mayor tasa de síntesis de astaxantina (Wang et al., 2013). Con base en lo anterior, se puede deducir que en este experimento hubo una adecuada fijación fotosintética debido a que el biorreactor Tecferm presenta una forma tubular que hace que la luz se distribuya a todo el cultivo, lo cual, posiblemente, fue un factor determinante en la producción de biomasa adecuada de H. pluvialis.

Actualmente, compañías dedicadas a la producción comercial de astaxantina a partir de microalgas (Cyanotech y Aquasearch) recurren a un sistema compuesto por dos etapas. La primera de ellas, conocida como "etapa verde", consiste en producir biomasa verde en condiciones óptimas de crecimiento. La segunda, denominada "etapa roja", inicia cuando la microalga es expuesta a condiciones ambientales adversas para inducir la acumulación de astaxantina (Wang et al., 2013). Es aquí donde la suplementación con acetato de sodio puede ser implementada desde el día 15, debido a que esto contribuye a un rendimiento adecuado en cuanto a la producción de biomasa y la formación de quistes, los cuales son la forma celular adecuada para la acumulación de astaxantina.

En cuanto a la concentración de astaxantina, para el tratamiento con $0,299 \mathrm{mg} / \mathrm{L}$ de acetato de sodio la mayor concentración de astaxantina se obtuvo en el día 20 , siendo igual a $2,530 \mu \mathrm{g} / \mathrm{mL}$, posteriormente alcanzando una cifra de $1,161 \mu \mathrm{g} / \mathrm{mL}$ en el día 34 . Por su parte, con el tratamiento con $1,6 \mathrm{mg} / \mathrm{L}$ se obtuvo una elevada concentración de astaxantina en el día 13, equivalente a $1,991 \mu \mathrm{g} / \mathrm{mL}$, que para el día 34 llegó a 1,5 $\mu \mathrm{g} / \mathrm{mL}$. Estos resultados pueden ser correlacionados perfectamente con el recuento celular obtenido para esos días. Por otro lado, en cuanto a la concentración de clorofila sucedió algo similar, ya que el tratamiento de $0,299 \mathrm{mg} / \mathrm{L}$ registró una mayor concentración en el día 20 , con $28,706 \mu \mathrm{g} / \mathrm{mL}$, y en el día 34 alcanzó una cifra de 16,637 $\mu \mathrm{g} / \mathrm{mL}$. Finalmente, para el tratamiento con 1,6 mg/ L se halló una mayor concentración en el día 13 , con $17,402 \mu \mathrm{g} / \mathrm{mL}$, resultado que llegó a $6,752 \mu \mathrm{g} / \mathrm{mL}$ en el día 34 .

Aunque la concentración de clorofila fue disminuyendo a medida que se acercaba el final del estudio, la concentración de astaxantina iba en aumento, lo cual era lo realmente importante del proyecto. No obstante, se observó que durante todo el estudio en ambos tratamientos la clorofila y la astaxantina fueron inversamente proporcionales, lo que coincide con lo descrito por la mayoría de los autores consultados (Camacho-Kurmen et al., 2013; Infant-Santhose et al., 2014; \& Wang et al., 2013). Así, se reafirma que el estudio puede ser llevado en "etapa verde" hasta el día 20 , ya que en este se obtiene una buena producción 
de biomasa. Después de este día se puede suministrar inyecciones directas de $\mathrm{CO}_{2}$, acetato de sodio y alta irradiancia con fotoperíodos de $20 \mathrm{~h}$ luz y $4 \mathrm{~h}$ oscuridad con el fin de generar el estrés indicado para la iniciación de la "etapa roja". Con ello, las células dan inicio al verdadero estrés y la acumulación de astaxantina, por lo que a futuro se genera una buena obtención de esta.

Las inyecciones de $\mathrm{CO}_{2}$ también pueden ser sustentadas gracias a que contribuyen a regular el $\mathrm{pH}$, lo que es un claro ejemplo de lo observado en el tratamiento con $1,6 \mathrm{mg} / \mathrm{L}$ de acetato de sodio, donde el aumento de $\mathrm{pH}$ fue una posible causa de que la velocidad de crecimiento celular fuera menor, en comparación al tratamiento con 0,299 $\mathrm{mg} / \mathrm{L}$, el cual presentó un $\mathrm{pH}$ más neutral y una mejor velocidad de crecimiento celular. Por esta razón, se sugiere que la inyección directa de $\mathrm{CO}_{2} \mathrm{O}$ adición de bicarbonato de sodio se sume a las condiciones de trabajo para los estudios de escalamiento de $H$. pluvialis.

Todos los resultados obtenidos hasta el día 20 se deben a la etapa de crecimiento o "etapa verde", que generalmente dura de 9 a 20 días, según la relación entre la biomasa celular y la actividad celular. Este hecho se pudo evidenciar en el estudio debido a que fue en este período en el que se obtuvo un mayor crecimiento celular. Posteriormente, llegando a la etapa de acumulación de astaxantina o "etapa roja", la morfología de aplanospora cambia por la disminución de nutrientes. De esta manera, se deduce que para obtener mejores resultados se puede ensayar la aplicación de acetato de sodio a partir del día 15 o 20, y no desde el primer día, puesto que los estudios que han reportado mejores rendimientos han aplicado el estímulo desde el día 15, sin importar su fuente de carbono (Camacho-Kurmen et al., 2013).

Con el uso de biorreactores de $500 \mathrm{~mL}$, donde se trabajó con 5 tratamientos usando los factores de estrés acetato de sodio, cloruro de sodio y alta irradiancia y un control (RM1), se estableció en las curvas de crecimiento de la microalga $H$. pluvialis que la fase exponencial se presentó en diferentes días del estudio. Se utilizó también el medio RM, el cual provee los nutrientes adecuados para el crecimiento de $H$. pluvialis, como lo han reportado Leiton-Arcos (2018), Imamoglu et al. (2007) y Niño-Castillo et al. (2017). En este estudio se observó que el mayor conteo celular fue de $2,69 \times 10^{5} \mathrm{cel} / \mathrm{mL}$ en medio RM1 (control), seguido por $1,45 \times 10^{6} \mathrm{cel} / \mathrm{mL}$, correspondiente al tratamiento RM6, al cual se le adicionó $0,320 \mathrm{mg} / \mathrm{L}$ de acetato de sodio y $1,28 \mathrm{mg} / \mathrm{L}$ de cloruro de sodio en el día 15 del cultivo. Así, se concluye que estas concentraciones de sales no logran el estrés suficiente para inhibir el crecimiento celular. De otro lado, el análisis de varianza (ANOVA) de crecimiento celular para los cinco tratamientos y el control identificó diferencias significativas entre estos ( $P$ $<0,05)$, con una confianza del $95 \%$.

El estudio de Goksan et al. (2010), donde se utilizó acetato de sodio ( $1 \mathrm{~g} / \mathrm{l}$ ) para comparar si se debía añadir este compuesto junto con los nutrientes orgánicos al comienzo del cultivo, como en la mixotrofía tradicional (MT), o al final de la fase logarítmica en modo fotótrofo, como mixotrofía alternativa (MA), concluyó que el peso seco (DW), los pigmentos y el número de células, particularmente, fueron más altos en la mixotrofía alternativa que en la tradicional (InfantSanthose et al., 2014; Rodríguez, 2019).

Al respecto, en esta investigación el número de células en MA pasó de 2,17 a 4,29 × $10^{5} \mathrm{cel} / \mathrm{mL}$ durante 5 días de exposición a acetato de sodio (casi el doble), mientras que en MT este incremento fue de solo 1,2 veces. Esto indica que en próximos estudios podría ser más eficiente agregar el acetato de sodio de una forma mixotrófica alternativa (MA), es decir, al final de la fase exponencial, ya que así se puede minimizar el riesgo de contaminación debido a la menor exposición de las células a las fuentes de carbono orgánico; sobre todo si el objetivo es obtener el máximo recuento posible de la microalga. Sin embargo, es necesario tener en cuenta la concentración de acetato de sodio adicionado, puesto que en el tratamiento donde se usó $1,6 \mathrm{mg} / \mathrm{L}$ de acetato de sodio desde el inicio del cultivo y la adición de cloruro de sodio a los 15 días mejoró la producción de astaxantina, lo que se debe a que el acetato de sodio fue utilizado como fuente de carbono, generando así una mayor producción de biomasa, que luego fue estresada con la combinación de cloruro de sodio y luz blanca alta con fotoperíodo de $20 \mathrm{~h}$ luz:4 $\mathrm{h}$ oscuridad e irradiancia de 75 lux. En contraste, en el tratamiento donde se utilizó el estrés con acetato de sodio, cloruro de sodio y luz alta con el fotoperíodo mencionado no se logró una buena biomasa ni una buena producción de astaxantina, registrando 
una disminución de $71 \%$ en su contenido. Lo anterior permite observar el impacto de la concentración de acetato de sodio de $1,6 \mathrm{mg} / \mathrm{L}$ sobre el crecimiento celular del H. pluvialis.

En los medios de cultivo macroscópicamente se observa un cambio de color rojizo en el medio RM3 desde el día 1 y en los medios RM2, RM5 y RM6 en el día 24, hallazgos congruentes con la observación microscópica realizada para analizar la evolución de la morfología de la microalga mediante su proceso de producción de astaxantina, observándose cambios morfológicos desde las formas vegetativas verdes hasta las aplanosporas y las formas enquistadas con color rojo. Estos resultados van en línea con lo reportado por Su et al. (2014), quienes tras someter a la microalga a condiciones de estrés con alta intensidad de luz y la aplicación de acetato de sodio lograron evidenciar que a los dos días las células se volvían ligeramente rojizas, indicando así la transición a aplanospora.

Con respecto a los resultados obtenidos para la producción de astaxantina, se logra evidenciar un aumento en el contenido de este pigmento, así como una disminución de la concentración de clorofila. Estos hallazgos soportan los resultados de Vidhyavathi et al. (2008), quienes tras 9 días de experimentación bajo condiciones de estrés reportan que el contenido total de clorofila en los tratamientos analizados fue $90 \%$ menor que el contenido de células móviles verdes registrado al inicio de su investigación.

Por su parte, el estudio de Wayama et al. (2013) realizó una evaluación volumétrica cuyo resultado logró evidenciar cambios drásticos en la transición entre la etapa verde y la etapa roja. En la etapa verde, los cloroplastos representaron $41,7 \%$ del volumen total de células, mientras que el volumen total de astaxantina fue de 0,2 \%, observando cloroplastos altamente desarrollados en la periferia y pocos gránulos de astaxantina rodeando el núcleo. En la etapa roja, las gotas de aceite que contenían astaxantina predominaron, con un $52 \%$, y el volumen total de cloroplastos disminuyó a 9,7 \%, observándose gotas de aceite grandes en toda la célula y cloroplastos altamente degenerados y localizados en el espacio intermedio entre las gotas de aceite, lo que les daba una apariencia de color rojo. Es importante aclarar que los cloroplastos no desaparecieron completamente, lo cual pudo deberse a que estos serían utilizados en una recuperación rápida cuando las condiciones ambientales se reestablecieran y la descomposición de clorofila fuera inducida por la deficiencia de nutrientes (Wayama et al., 2013), lo cual también se observó en esta investigación (Rodríguez, 2019).

Según los resultados obtenidos, el medio RM3, al cual se le adicionó $1,6 \mathrm{mg} / \mathrm{L}$ de acetato de sodio desde el inicio del cultivo y una adición de $6,4 \mathrm{mg} / \mathrm{L}$ de cloruro de sodio el día 15 , presentó la mayor producción de astaxantina, con una concentración de $7,3 \mu \mathrm{g} / \mathrm{L}$, que es congruente con los resultados obtenidos por Domínguez-Bocanegra et al. (2004), quienes utilizaron $1 \mathrm{~g} / \mathrm{L}$ de acetato de sodio junto con iluminación continua, obteniendo una producción máxima de astaxantina de $98 \mathrm{mg} / \mathrm{g}$ de biomasa. Así mismo, estos hallazgos son equiparables con los resultados de Cifuentes et al. (2003), quienes buscaron establecer condiciones óptimas para la producción de biomasa y astaxantina al someter a la microalga a condiciones mixotróficas (acetato de sodio con concentraciones de 4,8 y $12 \mathrm{mM}$, alta irradiancia de luz y cloruro de sodio al $0,8 \%$ ), con lo que obtuvieron un contenido de astaxantina por peso seco de 10,3 $\mathrm{mg} \mathrm{g}^{-1}(1 \% \mathrm{p} / \mathrm{p})$, identificando además que la adición simultánea de acetato de sodio/ $\mathrm{NaCl}$ en una concentración de 4,4/17,1 mM aumenta la producción de astaxantina.

Según el análisis de expresión de genes relacionados con la producción de carotenoides durante la inducción de estrés realizado por Vidhyavathi et al. (2009), la adición de acetato de sodio y cloruro de sodio produce una transcripción temprana y una regulación máxima positiva de genes como BKT ( $\beta$-caroteno cetolasa), el cual se encarga de la transformación de zeaxantina a adonixantina y de adonixantina a astaxantina, desde tres días de estrés hasta tres meses después (Vidhyavathi et al., 2008). Esto explicaría los resultados obtenidos en esta investigación, donde se observa una mayor producción de astaxantina al someter la microalga a estrés salino, ya que, como se mencionó previamente, la combinación de estos dos factores de estrés con la alta irradiancia con luz blanca (TIt 20w/54RS marca Philips) y fotoperíodo de 4 horas oscuridad y no 6 horas oscuridad, aumenta la producción de este compuesto, considerando que estos carotenoides 
se acumulan en estructuras especiales tales como plastoglóbulos de plástidos o cuerpos lipídicos citoplasmáticos, jugando un papel importante en la prevención del exceso de la energía lumínica del alcance de la maquinaria fotosintética (Richmond \& Hu, 2013; Rodríguez, 2019).

Esta investigación destaca la importancia del uso del biorreactor Tecferm de 5 litros para producir biomasa de la microalga, ya que bajo las condiciones trabajadas se obtuvo una biomasa adecuada, la cual, una vez finalizada su fase exponencial, puede ser sometida a factores de estrés con acetato de sodio y cloruro de sodio combinados con alta irradiancia, con lo que se puede obtener una mayor producción de astaxantina.

\section{CONCLUSIONES}

Los biorreactores de sistemas cerrados, como el utilizado en este estudio (biorreactor Tecferm de 5 Litros), proporcionan condiciones adecuadas para el crecimiento de la microalga $H$. pluvialis debido a que protegen el cultivo de la contaminación y controlan las condiciones de cultivo, permitiendo obtener una concentración de astaxantina de $2,530 \mu \mathrm{g} / \mathrm{mL}$ a través del uso de 0,299 $\mathrm{mg} / \mathrm{L}$ de acetato de sodio. La mayor productividad de astaxantina $(7,325 \mu \mathrm{g} /$ $\mathrm{mL}$ ) fue obtenida con la combinación de 1,6 mg/L de acetato de sodio desde el inicio del cultivo y la adición de cloruro de sodio $(6,4 \mathrm{mg} / \mathrm{L})$ a los 15 días del cultivo, con un incremento de $65 \%$ mediante el uso de biorreactores de $500 \mathrm{~mL}$. A partir de estos resultados, se establece la factibilidad tecnológica de cultivar inicialmente la microalga utilizando el biorreactor Tecferm de 5 litros, para luego de su fase exponencial someterla a factores de estrés combinando el uso de acetato de sodio, cloruro de sodio y luz de alta intensidad.

\section{AGRADECIMIENTOS}

A Laura M. García y Laura Johanna Rodríguez R., a la Universidad Colegio Mayor de Cundinamarca por el apoyo en la realización de este proyecto, y a la Universidad de La Sabana, Grupo de Investigación en Procesos Agroindustriales (GIPA).

\section{REFERENCIAS}

American Public Health Association [APHA]. (1992). Standard methods for the examination of water and wastewater (18 ed.). American Public Health Association (APHA), American Water Works Association (AWWA), \& Water Pollution Control Federation (WPCF).

Camacho-Kurmen, J. E., González, G., \& Klotz, B. (2013). Astaxanthin production in Haematococcus pluvialis under different stress conditions. Nova, 11(19), 94-104. https://doi. org/10.22490/24629448.1022

Cifuentes, A., González, M., Vargas, S., Hoeneisen, M., \& González N. (2003). Optimization of biomass, total carotenoids and astaxanthin production in Haematococcus pluvialis Flotow strain Steptoe (Nevada, USA) under laboratory conditions. Biol Res., 36, 343-357. https://doi. org/10.4067/S0716-97602003000300006

Domínguez-Bocanegra, A. R., Legarreta, I. G., \& Jeronimo, F. M. (2004). Campocosio AT. Influence of environmental and nutritional factors in the production of astaxanthin from Haematococcus pluvialis. Bioresource Technology, 92(2), 209-214. https://doi.org/10.1016/j.biortech.2003.04.001

García, M. L. (2018). Producción biotecnológica de astaxantina a partir Haematococcus pluvialis. Universidad Colegio Mayor de Cundinamarca.

Giannelli, L., Yamada, H., Katsuda, T., \& Yamaji, H. (2015). Effects of temperature on the astaxanthin productivity and light harvesting characteristics of the green alga Haematococcus pluvialis. Journal of Bioscience and Bioengineering, 119(3), 345350. https://doi.org/10.1016/j.jbiosc.2014.09.002

Goksan T, Ak, I., \& Gokpinar, S. (2010). An alternative approach to the traditional mixotrophic cultures of Haematococcus pluvialis Flotow (Chlorophyceae). Journal of Microbiology and Biotechnology, 20(9), 1276-1282. https://doi. org/10.4014/jmb.0909.09005

Gómez, L., Orozco, M. I., Quiroga, C., Díaz, J. C., Huérfano, J., Díaz, L. E., Rodríguez, J., \& Camacho, J. E. (2019). Producción de astaxantina y expresión de genes en Haematococcus pluvialis 
(Chlorophyceae, Volvocales) bajo condiciones de estrés por deficiencia de nitrógeno y alta irradiancia. Mutis, 9(2), 7-24. https://doi. org/10.21789/22561498.1532

González, M. A, Cifuentes, A. S, \& Gómez, P. I. (2009). Growth and total carotenoid content in four Chilean strains of Haematococcus pluvialis Flotow, under laboratory conditions. Gayana. Botanica, 66(1), 58-70. https://doi.org/10.4067/ S0717-66432009000100006

He, B., Hou, L., Dong, M., Shi, J., Huang, X., Ding, Y., Cong, X., Zhang, F., Zhang, X., \& Zang, X. (2018). Transcriptome analysis in Haematococcus pluvialis: Astaxanthin induction by high light with acetate and Fe2+. International Journal of Molecular Sciences, 19(1), 175. https://doi. org/10.3390/ijms19010175

Imamoglu, E., Vardan-Sukan, F., \& Conk-Dalay, M. (2007). Effect of different culture media and light intensities on growth of Haematococcus pluvialis. International Journal of Natural and Engineering Sciences, 1(3), 5-9. https://doi.org/10.1007/ s11738-002-0058-9

Infant-Santhose, B., Elumalai, S., \& Rajesh-Kanna, G. (2014). Airlift photobioreactor cultivation of a new strain of Haematococcus pluvialis collected from high altitude regions of Himalayas. International Journal of Science and Research, 3(10), 2289-2292.

Jeon, Y. C, Cho, C. W., Yun, Y. S. (2006). Combined effects of light intensity and acetate concentration on the growth of unicellular microalga Haematococcus pluvialis. Enzyme and Microbial Technology, 39(3), 490-495. https://doi. org/10.1016/j.enzmictec.2005.12.021

Lababpour, A., \& Lee, C. G. (2006). Simultaneous measurement of chlorophyll and astaxanthin in Haematococcus pluvialis cells by first-order derivative ultraviolet-visible spectrophotometry. Journal of Bioscience and Bioengineering, 101(2), 104-110. https://doi. org/10.1263/jbb.101.104
Leiton-Arcos, Y. A. (2018). Producción de Haematococcus pluvialis en el biorreactor Tecferm de 5 L en medios de cultivo RM y BBM. Universidad Colegio Mayor de Cundinamarca.

Lv, H., Xia, F., Liu, M., Cui, X., Wahid, F., \& Jia, S. (2016). Metabolomic profiling of the astaxanthin accumulation process induced by high light in Haematococcus pluvialis. Algal Research, 20, 3543. https://doi.org/10.1016/j.algal.2016.09.019

Ma, R., Thomas-Hall, S. R., Chua, E. T., Alsenani, F., Eltanahy, E., Netzel, M. E., Netzel, G., Lu, Y., \& Schenk, P. M. (2018). Gene expression profiling of astaxanthin and fatty acid pathways in Haematococcus pluvialis in response to different LED lighting conditions. Bioresource Technology, 250, 591-602. https://doi. org/10.1016/j.biortech.2017.11.094

Niño-Castillo, C. M., \& Rodríguez-Rivera F. C. (2015). Evaluación de las condiciones de crecimiento celular y factores de estrés para la producción de astaxantina a partir de la microalga Haematococcus pluvialis. Universidad Colegio Mayor de Cundinamarca.

Niño-Castillo, C. M., Rodríguez-Rivera, F. C., Díaz, L. E., \& Lancheros-Díaz, A. G. (2017). Evaluation of cell growth conditions for the astaxanthin production as of Haematococcus pluvialis. Microalgae Nova, 15(28), 19-31. https://doi. org/10.22490/24629448.2073

Pan-utai, W., Parakulsuksatid, P., \& Phomkaivon, N. (2017). Effect of inducing agents on growth and astaxanthin production in Haematococcus pluvialis: organic and inorganic. Biocatalysis and Agricultural Biotechnology, 12, 152-158. https:// doi.org/10.1016/j.bcab.2017.10.004

Park, J. C., Choi, S. P., Hong, M. E., \& Sim, S. J. (2014). Enhanced astaxanthin production from microalga Haematococcus pluvialis by two-stage perfusion culture with stepwise light irradiation. Bioprocess and Biosystems Engineering, 37(10), 2039-2047. https://doi.org/10.1007/s00449-014-1180-y 
Ramírez-Landínez, D. M. (2013). Evaluación del crecimiento y producción de astaxantina por Haematococcus pluvialis en un fotobiorreactor tipo airlift (tesis de maestría, Universidad Nacional de Colombia). Repositorio UN.

Ranga, R., Sarada, A., Baskaran, V., \& Ravishankar, G. (2009). Identification of carotenoids from green alga Haematococcus pluvialis by HPLC and LCMS (APCI) and their antioxidant properties. J Microbiol Biotechnol., 19, 1333-1341

Richmond, A., \& Hu, Q. (eds.). (2013). Handbook of microalgal culture. John Wiley \& Sons. https:// doi.org/10.1002/9781118567166

Rodríguez, R. L. J. (2019). Producción de astaxantina en Haematococcus pluvialis bajo efecto de factores de estrés como acetato de sodio y cloruro de sodio combinadas con alta intensidad de luz. Universidad Colegio Mayor de Cundinamarca.

Sugawara, T., \& Maoka, T. (2021). Marine carotenoids. MDPI.

Shah, M. M. R., Liang, Y., Cheng, J. J., \& Daroch, M. (2016) Astaxanthin-producing green microalga Haematococcus pluvialis: From single cell to high value commercial products. Front Plant Sci., 28(7), 531. https://doi.org/10.3389/fpls.2016.00531

Shakhmatov, A. S., Pavlovskiy, E. V., \& Paukov, A. G. (2018). Desmid algae (Charophyta: Conjugatophyceae) of Ekaterinburg, Middle Urals, Russia. Folia Cryptogamica Estonica, 55, 7-15. https://doi.org/10.12697/fce.2018.55.02

Su, Y., Wang, J., Shi, M., Niu, X., Yu, X., Gao, L., Zhang, X., Chen, L., \& Zhang, W. (2014). Metabolomic and network analysis of astaxanthin-producing Haematococcus pluvialis under various stress conditions. Bioresource Technology, 170, 522-529. https://doi.org/10.1016/j.biortech.2014.08.018

The University of Texas at Austin (UTEX). (2019, septiembre 20). Algae culturing medium. https:// utex.org/products/volvox-medium
Tocquin, P., Fratamico, A., \& Franck, F. (2012). Screening for a low-cost Haematococcus pluvialis medium reveals an unexpected impact of a low N/P ratio on vegetative growth. Journal of Applied Phycology, 24(3), 365-373. https://doi. org/10.1007/s10811-011-9771-3

Vásquez-Perea, Y., Villamil-Poveda, J., Sánchez-Leal, L., \& Lancheros-Díaz, A. (2014). Evaluación de un sistema de medio fijo como soporte para una película microbiana capaz de reducir $\mathrm{Cr}(\mathrm{VI})$ de lodos residuales de curtiembres. $g$, 12(21), 5766. https://doi.org/10.22490/24629448.996

Vidhyavathi, R., Venkatachalam, L., Sarada, R., \& Ravishankar, G. A. (2008). Regulation of carotenoid biosynthetic genes expression and carotenoid accumulation in the green alga Haematococcus pluvialis under nutrient stress conditions. Journal of Experimental Botany, 59(6), 1409-1418. https://doi.org/10.1093/jxb/ern048

Vidhyavathi, R., Sarada, R., \& Ravishankar, G. A. (2009). Expression of carotenogenic genes and carotenoid production in Haematococcus pluvialis under the influence of carotenoid and fatty acid synthesis inhibitors. Enzyme and Microbial Technology, 45(2), 88-93. https://doi. org/10.1016/j.enzmictec.2009.05.005

Wan, M., Zhang, J., Hou, D., Fan, J., Li, Y., Huang, J., \& Wang, J. (2014). The effect of temperature on cell growth and astaxanthin accumulation of Haematococcus pluvialis during a light-dark cyclic cultivation. Bioresource Technology, 167, 276-283. https://doi.org/10.1016/j.biortech.2014.06.030

Wang, J., Han, D., Sommerfeld, M. R., Lu, C., \& Hu, Q. (2013). Effect of initial biomass density on growth and astaxanthin production of Haematococcus pluvialis in an outdoor photobioreactor. Journal of Applied Phycology, 25(1), 253-260. https://doi. org/10.1007/s10811-012-9859-4

Wang, N., Guan, B., Kong, Q., Sun, H., Geng, Z., \& Duan L. (2016). Enhancement of astaxanthin production from Haematococcus pluvialis mutants by three-stage mutagenesis breeding. 
Journal of Biotechnology, 236, 71-77. https://doi. org/10.1016/j.jbiotec.2016.08.009

Wayama, M., Ota, S., Matsuura, H., Nango, N., Hirata, A., \& Kawano, S. (2013). Three-dimensional ultrastructural study of oil and astaxanthin accumulation during encystment in the green alga Haematococcus pluvialis. PloS One, 8(1), e53618. https://doi.org/10.1371/journal.pone.0053618

Woong, C., Jeon, Y., \& Sang, Y. (2006). Combined effects of light intensity and acetate concentration on the growth of unicellular microalga Haematococcus pluvialis. Rev Enzyme and Microbial Technology, 39(3), 490-495. https://doi.org/10.1016/j.enzmictec.2005.12.021
Xi, T., Kim, D. G., Roh, S. W., Choi, J. S., \& Choi, Y. E. (2016). Enhancement of astaxanthin production using Haematococcus pluvialis with novel LED wavelength shift strategy. Applied Microbiology and Biotechnology, 100(14), 6231-6238. https:// doi.org/10.1007/s00253-016-7301-6 